\title{
Recomendaciones generales sobre durabilidad
} \section{Técnicas}

Recomendaciones

\section{Pedro Castro Borges}

3. Jorge Alberto Briceño Mena

\section{Andrés Antonio Torres Acosta}

https://oi.org/10.21041/AlconpatInternacional/RecTec/2020-01-recomendacionesdedurabilidad

\section{ALCONPAT Internacional}

Asociación Latinoamericana de Control de Calidad, Patología y Recuperación de la Construcción

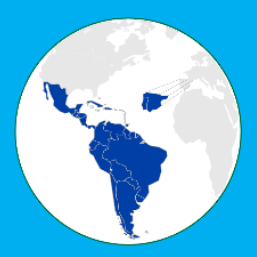




\section{ReCOMENDACIÓN TÉCNICA}

Editores

Pedro Garcés Terradillos

Director de Recomendaciones Técnicas Universidad de Alicante, España
Jorge Alberto Briceño Mena

Subdirector de Recomendaciones Técnicas Cinvestav del IPN, Unidad Mérida, Mérida, Yucatán, México

\section{Recomendaciones generales sobre durabilidad}

DOI: https://doi.org/10.21041/AlconpatInternacional/RecTec/2020-01recomendacionesdedurabilidad

Recomendações gerais sobre durabilidade

\section{General recommendations on durability}

\section{Pedro Castro Borges}

Centro de Investigación y de Estudios Avanzados del IPN, Unidad Mérida Mérida, Yucatán, México

\section{Jorge Alberto Briceño Mena}

Centro de Investigación y de Estudios Avanzados del IPN, Unidad Mérida Mérida, Yucatán, México

\section{Andrés Antonio Torres Acosta}

Instituto Tecnológico y de Estudios Superiores de Monterrey: Querétaro, Querétaro, México 


\section{Recomendación Técnica No. 1}

\section{DURABILIDAD}

\section{OBJETIVO}

Esta Recomendación Técnica tiene como objeto proporcionar reglas, procedimientos, métodos, criterios y recomendaciones para concebir, proyectar, ejecutar, inspeccionar, diagnosticar, reparar, rehabilitar o reforzar estructuras de concreto con criterios de durabilidad que se encuentren sometidas a distintos tipos de ambientes.

\section{INTRODUCCIÓN}

Hasta hace unos años no se había reflejado específicamente el reconocimiento de los problemas de durabilidad, pero el contexto actual demanda la incorporación y utilización del conocimiento existente relativo al tema. Por ello surge la necesidad de establecer recomendaciones técnicas que se adapten a las circunstancias y los ambientes que las estructuras de concreto reforzado demandan en materia de durabilidad.

Esta recomendación técnica es aplicable a todo elemento $\mathrm{u}$ obra de concreto incluyendo su concepción, proyección, ejecución, inspección, diagnóstico, reparación, rehabilitación o refuerzo, hasta el final de su vida de servicio, con criterios de durabilidad y que se encuentre sometida a distintos tipos de ambientes.

Para seguir esta recomendación técnica es importante tener clara la responsabilidad de cada uno de los actores, desde el proyecto hasta la disposición final de la estructura.

La responsabilidad de que una obra cumpla con la durabilidad de proyecto durante toda su vida se atribuye al correcto desempeño de un grupo de profesionistas, los cuales tienen la responsabilidad de que dentro de su interacción directa o indirecta con la obra se cumplan los criterios requeridos para la durabilidad de la misma. Entre ellos se considera más no se limita a:

\subsection{Dueño de la obra}

En él recae gran parte de la responsabilidad ya que es el único que interactúa durante toda la obra desde su concepción hasta el término de su vida de servicio.

\subsection{Director responsable de obra (DRO, perito de obra o equivalente)}

Es la persona física que acredita fehacientemente su conocimiento de las leyes y disposiciones reglamentarias relativas a la construcción, que cuenta con cédula profesional y que ante las autoridades correspondientes y el propietario de la obra se hace responsable de la calidad del proyecto, de la supervisión y/o ejecución de la obra con el objetivo de cumplir 
con las normas, los reglamentos de construcción y las especificaciones del proyecto a fin de realizar una obra de calidad definida, para la cual otorga su responsiva profesional.

Algunas regulaciones locales requieren, además, para ciertas edificaciones corresponsables como los que a continuación se señalan.

\subsubsection{Especialista responsable estructural}

Es la persona que por encargo del dueño y con base en la normativa correspondiente realiza el proyecto estructural de la obra en cualquiera de las etapas de su vida de servicio; debiendo demostrar su acreditación académica y profesional

\subsubsection{Especialista responsable en arquitectura}

Es la persona que por encargo del dueño y con base en la normativa correspondiente realiza el proyecto arquitectónico de la obra en cualquiera de las etapas de su vida de servicio; debiendo demostrar su acreditación académica y profesional

\subsubsection{Especialista responsable en durabilidad}

Es un profesionista certificado, que es responsable de la obra, en cualquiera de sus (las) etapas de su vida de servicio, de hacer las inspecciones tanto preliminar como detallada, así como de emitir un dictamen sobre su seguridad estructural, durabilidad y confiabilidad. El especialista responsable en durabilidad trabaja en estrecha colaboración con el especialista responsable estructural y el especialista responsable en arquitectura.

\subsubsection{Constructor}

Se encarga de dirigir el desarrollo de la obra en cualquiera de las etapas de su vida de servicio considerando los aspectos técnicos y estéticos, y conforme al proyecto y la licencia de edificación dada.

\subsubsection{Proveedor}

Es aquel encargado de suministrar materiales de la calidad especificada a la obra en cualquiera de las etapas de su vida de servicio y que cumpla con los compromisos de entrega pactado de acuerdo con lo solicitado.

\subsubsection{Supervisor}

Es el que dirige la ejecución material de la obra en cualquiera de las etapas de su vida de servicio, controlando se realice de conformidad con las especificaciones arquitectónicas y estructurales.

\section{TÉRMINOS, DEFINICIONES, SÍMBOLOS, UNIDADES Y TÉRMINOS ABREVIADOS}

\subsection{Absorción capilar}

Proceso de penetración de agua en el concreto, determinado por las características de capilaridad de la matriz de concreto. Definido como masa de agua por unidad de área que puede ser absorbida en los espacios capilares cuando el concreto se encuentra en contacto con agua en estado líquido. Representa la porosidad efectiva accesible al agua y por lo tanto a los agentes agresivos que se encuentran en el ambiente.

\subsection{Acero}

Aleaciones hierro-carbono, con un contenido máximo de carbono del 2\%, aproximadamente. El carbono dota al hierro de destacadas propiedades mecánicas, necesarias para sus aplicaciones industriales. 
Término que se refiere a un estado de los materiales metálicos en el que éstos tienden a corroerse, o a metales o aleaciones que se sitúan en el extremo de potenciales más negativos de las series electroquímicas o galvánicas y son muy corrosibles.

\subsection{Actividad}

Función termodinámica que expresa la capacidad de reaccionar de una sustancia, $\mathrm{a}_{\mathrm{i}}=\exp (\Delta \mathrm{G} / \mathrm{RT})$, donde $\Delta \mathrm{G}$ es la variación de energía libre de un mol de la especie i en la reacción, $\mathrm{T}$ la temperatura absoluta (K) y R la constante de los gases perfectos.

\subsection{Acuoso}

Se refiere a medios que contienen agua, en los que ésta actúa como electrolito o conductor iónico de la corriente eléctrica.

\subsection{Adherencia}

Fuerza de unión entre un recubrimiento cualquiera y el sustrato.

\section{7. Á $\overline{\text { ditivo }}$}

Es un material diferente del agua, de los agregados y del material cementante, que se puede emplear como componente del concreto o mortero y se agrega a la mezcla inmediatamente antes o durante el mezclado, modificando algunas características del concreto.

\subsection{Agrietamiento}

Roturas en el concreto siguiendo una trayectoria única o ramificada.

\section{9. Ânodo}

Electrodo de las pilas electroquímicas o electrolíticas en el que se produce la oxidación de alguna sustancia. En los fenómenos de corrosión, que suelen desarrollarse sobre electrodos mixtos, las zonas de mayor tendencia a disolverse, en las que los átomos metálicos se oxidan a cationes: $\mathrm{M}-\gg \mathrm{Mn}^{+}+\mathrm{ne}^{-}$. En los ánodos fluye corriente eléctrica positiva hacia el medio electrolítico (transferencia de cationes a la solución, o de aniones de la solución al electrodo.

\subsection{0. Änodo de sacrificio}

Una masa de metal muy electronegativo, como el aluminio, magnesio o zinc, que se conecta a la estructura a proteger por el método de protección catódica, con la que forma un par galvánico desplazando su potencial, en dirección negativa, hasta la zona de inmunidad

\subsection{Acero de refuerzo}

Conjunto de barras o cables de acero que se colocan dentro del concreto y hacen que el mismo sea apto para resistir esfuerzos de flexión, cortante, tensión, etc., o para incrementar su resistencia a la compresión. 
Elementos rectos y deformados de alambres de acero trefilado en frio, o recortes de acero de fibras rectas o deformadas, o fibras extraídas del proceso de la fundición, o fibras trefiladas modificadas en frio o fibras del corte de acería, que son adecuadas para su mezcla homogénea en el concreto o mortero.

\subsection{Capilaridad}

Fenómeno superficial de absorción de agua en el concreto. La capilaridad es una propiedad física del concreto por la que el líquido puede avanzar a través de sus poros capilares.

\subsection{Carbonatación}

Es un proceso químico de cinética relativamente lenta que ocurre en la pasta de cemento hidratada de un concreto; los silicatos de calcio y el hidróxido de calcio formados por la hidratación del cemento, reaccionan con el dióxido de carbono atmosférico formando carbonato de calcio. Esta reacción requiere de un medio acuoso, ya que el dióxido de carbono se disuelve en el agua formando ácido carbónico, el cual se disocia en iones carbonato; dichos iones reaccionan con los compuestos referidos formando carbonato de calcio y agua. Este proceso de reacción reduce el $\mathrm{pH}$ de la solución de poro del concreto. Cuando este fenómeno afecta a los poros situados en la interfase hacer-pasta se favorecen los procesos de corrosión del acero de refuerzo, comprometiendo la integridad estructural de las construcciones.

\subsection{Catión}

Ión cargado positivamente, que migra al cátodo en una celda electrolítica, o se produce en el ánodo de una celda electroquímica o pila de corrosión.

\subsection{Cátodo}

El electrodo de una pila de corrosión en el que tiene lugar el proceso de reducción. Procesos catódicos típicos de corrosión son la reducción de oxígeno en medios neutros o alcalinos $\left(\mathrm{O}_{2}+\right.$ $\left.2 \mathrm{H}_{2} \mathrm{O}+4 \mathrm{e}^{-} \rightarrow 4 \mathrm{OH}^{-}\right)$y la de protones en medios ácidos $\left(2 \mathrm{H}^{+}+2 \mathrm{e}^{-} \rightarrow \mathrm{H}_{2}\right)$.

\subsection{Concreto}

Es el material pétreo, artificial obtenido de la mezcla en porciones determinadas de cemento, agregados, agua y aditivos (en su caso).

\subsection{Concreto reforzàdo}

Concreto que en combinación con acero de refuerzo es capaz de resistir esfuerzos de compresión o tensión u otros esfuerzos.

\subsection{Corriente}

Flujo de cargas eléctricas a través de la sección de un material conductor por unidad de tiempo. 


\subsection{Corrosión}

La transformación de un metal del estado elemental al combinado (estado iónico) por reacción con el medio ambiente.

\subsection{Córrosión activa}

En este tipo de corrosión el metal se disuelve activamente, presentando productos de corrosión solubles.

\subsection{Corrosión galvánica o bimetálica}

Corrosión debida al par formado por dos metales diferentes en contacto eléctrico y expuestos a un electrolito, condición en la que el metal más electropositivo estimula la corrosión del más electronegativo y el primero se corroe menos que cuando se presenta aislado en el mismo medio.

\subsection{Curado}

Es el proceso mediante el cual, en un ambiente especificado de humedad y temperatura, se garantiza la hidratación del cemento o de los materiales cementantes en la mezcla.

\subsection{Defecto}

Carencia o imperfección de las cualidades propias del concreto.

\subsection{Deflexión}

Grado en el que el eje de un elemento estructural se desplaza bajo la aplicación de una fuerza.

\subsection{Dénsidàd de corriente}

Cantidad de corriente por unidad de tiempo y superficie. Suele expresarse en $\mathrm{A} / \mathrm{m}^{2}, \mathrm{~mA} / \mathrm{m}^{2}, \mathrm{~mA} / \mathrm{cm}^{2}$, $\mu \mathrm{A} / \mathrm{cm}^{2}$, etc.

\subsection{Desprendimiento}

Separación de fragmentos de una superficie o recubrimiento superficial, a causa de las tensiones generadas por la corrosión o por dilataciones y contracciones diferenciales.

\section{2. $\overline{\text { D. }}$ Durabìilidad}

Es la capacidad de un material de construcción, elemento o estructura de resistir las acciones físicas, químicas, biológicas, ambientales y cambio climático en su entorno durante un tiempo determinado previsto desde el proyecto, conservando su forma original, propiedades mecánicas y condiciones de servicio.

\subsection{Electrodo}

Conductor electrónico, normalmente metálico, por medio del cual se proporcionan los electrones necesarios a una reacción, o se consumen los electrones resultantes de la misma. 


\section{$\overline{2} . \overline{3} \overline{0} . \overline{E l e c t r o d o} \overline{d e}$ referencia}

Una semipila prácticamente impolarizable y de potencial constante, que sirve para medir y controlar el potencial del electrodo sometido a estudio en la célula de ensayo, refiriéndolo a una escala arbitraria (p.e., la escala de hidrógeno, de $\mathrm{Cu} / \mathrm{CuSO}_{4}$, de $\mathrm{Ag} / \mathrm{AgCI}$, etc.).

\subsection{Electrolito o conductor iónico}

Sustancia química, usualmente en solución acuosa, que contiene iones que migran bajo a acción de un campo eléctrico.

\subsection{Estructura}

Conjunto de elementos de una construcción cuya función es la de resistir las cargas y/o acciones para las que fue diseñada, incluyendo los efectos del medio ambiente al que esté sometido.

\subsection{Fugas}

Escape, salida accidental de un gas o líquido.

\subsection{Humedad relativa}

La relación de la cantidad de moléculas de agua en la atmósfera con relación a la cantidad máxima que puede tener una temperatura dada, expresada como un porcentaje.

\subsection{Inmunidad}

Estado en el que se controla la corrosión por imposición a la superficie metálica de potenciales más negativos que el potencial de equilibrio de la semireacción anódica de oxidación. Se acepta en la práctica que existe inmunidad cuando el potencial del electrodo es más negativo que el potencial de equilibrio a una concentración de iones metálicos de $10^{-6}$ moles/litro.

\subsection{Ión}

Un átomo o grupo de átomos (molécula) con carga eléctrica.

\subsection{Material cementante}

Es el material que al agregarle agua ya sea solo o mezclado con arena u otros materiales similares, tiene la propiedad de fraguar tanto al aire como bajo el agua y formar una masa endurecida.

\subsection{Mortero}

Mezcla de cemento, agregado fino y agua.

\subsection{Noble}

Se refiere al extremo más positivo, catódico o reductor de los potenciales de electrodo y también a los metales que se encuentran en estado libre (sin combinar) en la naturaleza. 


\subsection{Oxidación}

Pérdida de electrones en una reacción química o electroquímica, por ejemplo, en los procesos anódicos, cuando un metal pasa del estado metálico al de catión (estado oxidado, combinado o corroído).

\subsection{Oxidante}

Sustancia capaz de provocar la pérdida de los electrones a otra especie en una reacción química.

\subsection{Par galvánico}

Pila formada por dos metales distintos en contacto eléctrico e inmerso en el mismo electrolito.

\subsection{Pasivación}

Transición del estado activo al pasivo, de muchos metales u aleaciones en ciertos medios. Puede ser natural o forzada por una polarización anódica. Constituye una excepción de gran importancia práctica a la ley general en electroquímica, que establece velocidades de corrosión crecientes para polarizaciones anódicas también crecientes.

\subsection{Pasivo}

Estado que implica una reactividad muy pequeña, es decir, velocidades insignificantes de corrosión.

\subsection{5. $\mathrm{pH}$}

Medida de la acidez o alcalinidad de una solución. En sentido estricto, es el logaritmo del inverso de la actividad de iones hidrógeno en la solución: $\mathrm{pH}=-\log \mathrm{aH}^{+}$. El valor $7 \mathrm{de} \mathrm{pH}$ corresponde a una solución neutra; los valores inferiores a medios ácidos y los superiores a medios alcalinos.

\subsection{Polarización}

Es la diferencia matemática entre el potencial del electrodo para unas condiciones dadas de densidad de corriente y el potencial de corrosión o potencial en circuito abierto: $\eta=E$ - Ecorr. Usualmente se consideran sus componentes: polarizaciones de activación, de concentración y de resistencia.

\subsection{Polarización anódica}

Desplazamiento del potencial de electrodo resultante del flujo de corrientes positivas. El potencial se hace más positivo.

\subsection{Polarización catódica}

Efecto del flujo de corrientes negativas sobre el potencial de electrodo que se hace más negativo. 


\subsection{Porosidad}

Espacios vacíos formados por canales visibles o invisibles en un medio sólido discontinuo, como el concreto. También aplica a canales, muchas veces microscópicos, en un recubrimiento, metálico o no, que se extienden hasta el substrato.

\subsection{Potencial, medida de}

Diferencia de potencial de un electrodo (semipila o semielemento) definida con relación a otro electrodo específico, conocido como electrodo de referencia.

\subsection{Potencial de corrosión}

Es el potencial de un electrodo que se corroe en un medio dado, sin flujo de corriente externa que lo genere. Para el mismo concepto se emplean también los siguientes términos: potencial de circuito abierto; potencial de corrosión libre; potencial de reposo; potencial de abandono y potencial estacionario.

\subsection{Proporcionamiento del concreto}

Es el cálculo de las cantidades de materiales por unidad de volumen que se requieren para fabricar un concreto que tenga las características especificadas.

\subsection{Protección catódica}

Reducción o eliminación del fenómeno de corrosión de una superficie metálica, por medio de una polarización catódica que desplace su potencial hasta la zona de inmunidad. La protección catódica puede aplicarse uniendo la estructura al polo negativo de un rectificador (método de corriente impresa) o uniéndola a un metal muy electronegativo como el zinc, el aluminio o el magnesio (método de los ánodos de sacrificio).

\subsection{Recubrimiento de concreto}

Es la protección que le da el concreto al acero de refuerzo contra el medio ambiente. Es la distancia medida desde la superficie del concreto a la parte más cercana del acero de refuerzo (incluyendo a los zunchos, anillos y estribos).

\subsection{Reducción}

Proceso químico o electroquímico en el cual una sustancia gana electrones.

\subsection{Reductor}

Sustancia que causa la reducción de otras, cediéndoles o compartiendo electrones, al tiempo que ella se oxida. 


\subsection{Relación agua/material cementante}

La relación en masa de la cantidad de agua, excluyendo la absorbida por los agregados, a la cantidad de material cementante empleado en la mezcla.

\subsection{Resistencia a la compresión}

Es la capacidad de carga a compresión por unidad de área de un material, medida en ensayes descritos en las normas correspondientes, generalmente expresada en $\mathrm{kg} / \mathrm{cm}^{2}$.

\subsection{Revenimiento}

Es una medida de la consistencia del concreto fresco, que se refiere al grado de fluidez de la mezcla.

\subsection{Semielemento o semipila}

Un metal puro en contacto con una solución de sus propios iones origina, para sus condiciones dadas, un potencial característico y reproducible, que, en condiciones normales, es el potencial estándar o normal. Cuando una semipila se une a otra se puede medir una diferencia de potencial; y, si se hace con respecto al electrodo de hidrógeno, se obtiene directamente el potencial de la otra semipila.

\subsection{Substrato}

El material base sobre el que se aplican capas o depósitos.

\subsection{Velocidad de corrosión}

Cantidad de metal o aleación deteriorada (oxidada) por unidad de área y unidad de tiempo, en g/cm² (es decir, gramos por centímetro cuadrado y día). Puede expresarse en función de la penetración en el tiempo (mm/año, $\mu \mathrm{m} / \mathrm{año})$. 


\section{RECOMENDACIONES TÉCNICAS}

\subsection{Generalidades}

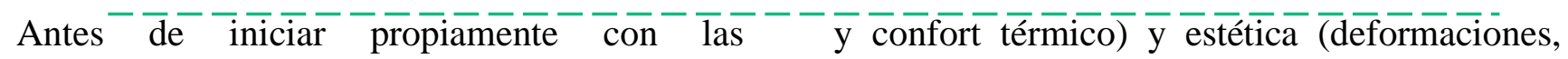
recomendaciones técnicas, es necesario tener en cuenta que la vida de servicio es "el tiempo durante el cual el desempeño de un material, elemento o estructura de concreto conserva las características del proyecto en términos de seguridad (resistencia mecánica y estabilidad, seguridad en caso de fuego, seguridad en uso), funcionalidad (higiene, salud y medio ambiente, protección contra el ruido y ahorro energético, agrietamientos, desprendimientos), con un mínimo de mantenimiento que le permita soportar los efectos ambientales y naturales en su entorno durante su uso."

De acuerdo con la definición de vida de servicio, su modelo conceptual consta de 7 etapas, presentando una división de acuerdo con la planificación de proyectos y predicciones de durabilidad durante su uso. (véase Figura 1)

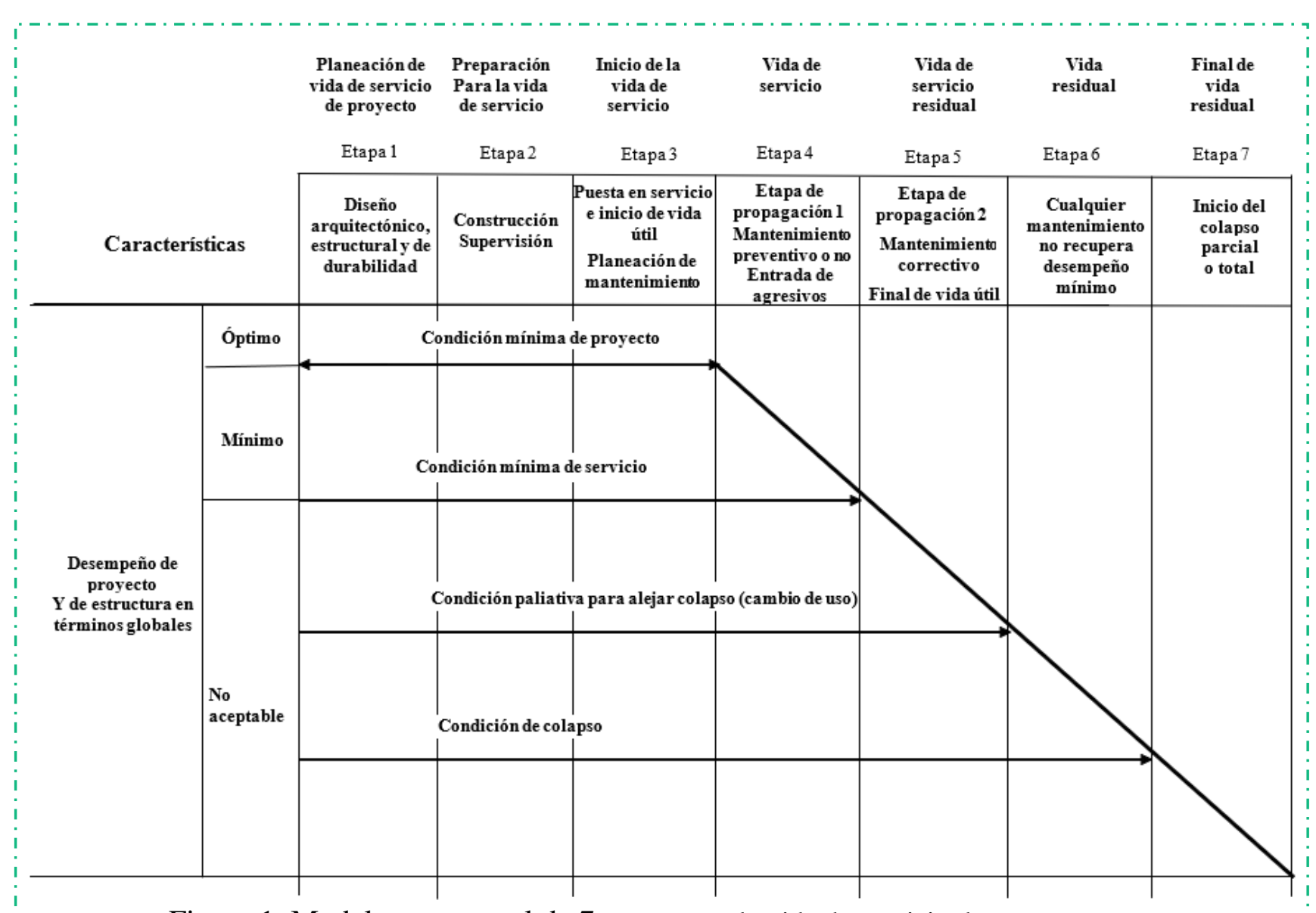

Figura 1. Modelo conceptual de 7 etapas para la vida de servicio de una estructura 


\subsection{Etapa 1. Planeación de vida de servicio de proyecto (diseño arquitectónico, estructural y de durabilidad)}

\subsubsection{Generalidades}

Ésta es la etapa más importante de la vida de servicio, pues es donde se establecen todos los criterios y especificaciones para cumplir con los objetivos para los que fue diseñada la estructura:

\subsubsection{Diseño arquitectónico}

En el diseño arquitectónico se deben incluir formas y materiales acordes con el uso de la estructura, tipo de ambiente al que va a estar expuesta y tiempo de Vida de Servicio propuesto. Debe abarcar hasta la etapa $4 \mathrm{y}$ aclarar que durante esa etapa deben tomarse acciones para las etapas subsecuentes. En esta etapa, los proyectistas deben vincularse estrechamente con el especialista en durabilidad, quien les provee de las herramientas necesarias para poder diseñar un proyecto que satisfaga las expectativas.

\subsubsection{Diseño estructural}

Aquí intervienen las técnicas de cálculo estructural, el especialista responsable estructural debe estar estrechamente vinculado al especialista en durabilidad para que puedan cumplirse las metas previstas. Debe abarcar hasta la etapa 4 y aclarar que durante esa etapa deben tomarse acciones para las etapas subsecuentes. Deben ser definidos parámetros tales como recubrimiento de concreto para acero, tipos de aceros, calidad y desempeño del concreto, etc., que influyen en la durabilidad de la estructura.

\subsubsection{Diseño por durabilidad}

Con base en la información disponible en códigos y reglamentos, el perito en durabilidad debe tomar en cuenta el ambiente al que va a estar expuesta la estructura y los materiales que se emplearán para poder ofrecer la vida de servicio esperada para la estructura. Se deben considerar aspectos como la agresividad química del medio y del suelo, atmósfera de exposición (HR y T), terremotos, huracanes o potenciales inundaciones, deben ser definidos pues influyen en la durabilidad de la estructura. Con base en éstos y otros parámetros definidos en la literatura nacional e internacional, debe establecerse la vida de servicio de la estructura a diseñar.

\subsubsection{Diseño del plan de mantenimiento.}

Esta parte es esencial para el proyecto pues es la que permite asegurar que las condiciones establecidas de vida de servicio (arquitectónica, estructural y durable) se cumplan. Es importante incluir las acciones de mantenimiento preventivo a seguir cuando la estructura se encuentre en una parte determinada de la etapa 3 , que es cuando se tiene que empezar a planear las acciones para las etapas subsecuentes. Se deben especificar en detalle aspectos como verificación periódica de daños (sea cual sea su origen), interacción entre los elementos e instalaciones de la misma estructura, mantenimiento periódico con pinturas, sustitución de piezas, funcionamiento de drenajes y manejo general de aguas, etc., deben ser cuidadosamente especificados. Deben incluirse también esquemas y formatos para llevar a cabo exitosamente el plan de mantenimiento, así como un entrenamiento periódico a los responsables de esta parte.

\subsubsection{Clasificación según el ambiente agresivo de exposición Consiste en clasificar los distintos tipos de ambientes que se encuentran sujetos a condiciones climáticas extremas (véase tabla 1). Los peritos en arquitectura, estructuras y durabilidad, así como el constructor deben tomar en cuenta estas condiciones para establecer las recomendaciones y especificaciones del elemento de concreto.}


Tabla 1. Clasificación de exposición ambiental

\begin{tabular}{|c|c|c|c|c|}
\hline \multicolumn{4}{|c|}{ CLASE GENERAL DE EXPOSICIÓN } & \multirow[b]{2}{*}{ Descripción } \\
\hline $\begin{array}{c}\text { Clase } \\
\text { (Ambiente de } \\
\text { exposición) }\end{array}$ & $\begin{array}{l}\text { Subclase } \\
\text { (Condición de } \\
\text { exposición) }\end{array}$ & $\begin{array}{l}\text { Tipo de } \\
\text { proceso }\end{array}$ & $\begin{array}{l}\text { Designación } \\
\text { (Clasificación) }\end{array}$ & \\
\hline No agresivo & Seco & 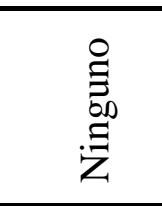 & $\mathrm{C} 0$ & $\begin{array}{l}\text { Concreto en ambiente seco o } \\
\text { protegido de la humedad y no } \\
\text { sometido a condensaciones. Con una } \\
\text { humedad relativa }<40 \% \text {. }\end{array}$ \\
\hline \multirow{3}{*}{ Rural / Urbana } & $\begin{array}{l}\text { Concreto en } \\
\text { contacto con } \\
\text { humedad alta }\end{array}$ & \multirow{3}{*}{ 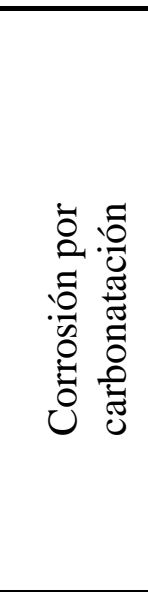 } & $\mathrm{C} 1$ & $\begin{array}{l}\text { Concreto en ambiente con alta } \\
\text { humedad relativa }>80 \%, \\
\text { independiente de la contaminación } \\
\text { por } \mathrm{CO}_{2} \mathrm{y} \mathrm{SO}_{2} .\end{array}$ \\
\hline & $\begin{array}{l}\text { Concreto en } \\
\text { contacto con } \\
\text { humedad baja }\end{array}$ & & $\mathrm{C} 2$ & $\begin{array}{l}\text { Concreto en ambiente con baja } \\
\text { humedad relativa entre } 40 \% \text { y } 50 \% \text {, } \\
\text { independiente de la contaminación } \\
\text { por } \mathrm{CO}_{2} \mathrm{y} \mathrm{SO}_{2} \text {. }\end{array}$ \\
\hline & $\begin{array}{c}\text { Concreto en } \\
\text { contacto con } \\
\text { humedad } \\
\text { moderada } \\
\end{array}$ & & $\mathrm{C} 3$ & $\begin{array}{l}\text { Concreto en ambiente con moderada } \\
\text { humedad relativa entre } 50 \% \text { y } 80 \% \text {, } \\
\text { con contaminación por } \mathrm{CO}_{2} \text { y } \mathrm{SO}_{2} \text {. }\end{array}$ \\
\hline \multirow{4}{*}{ Marina } & Sumergida & \multirow{6}{*}{ 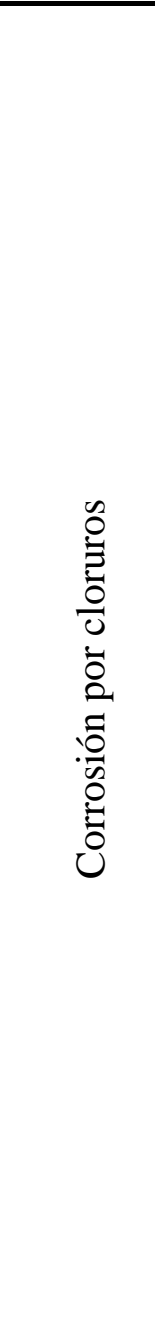 } & M1 & $\begin{array}{l}\text { Elementos de estructuras marinas } \\
\text { sumergidas permanentemente, por } \\
\text { debajo del nivel mínimo de bajamar. }\end{array}$ \\
\hline & \begin{tabular}{|c|} 
Zonas aéreas con \\
distancias de 50 \\
$\mathrm{~m}$ a $500 \mathrm{~m}$ a la \\
línea de costa \\
\end{tabular} & & M2 & $\begin{array}{l}\text { Elementos exteriores de estructuras } \\
\text { en las proximidades de la línea de } \\
\text { costa (de } 50 \mathrm{~m} \text { a } 500 \mathrm{~m}) .\end{array}$ \\
\hline & $\begin{array}{c}\text { Zonas aéreas con } \\
\text { distancias de } \\
0 \mathrm{~m} \text { a } 50 \mathrm{~m}\end{array}$ & & M3 & $\begin{array}{l}\text { Elementos de estructuras marinas por } \\
\text { encima del nivel de pleamar } \\
\text { (salpique) de } 0 \mathrm{~m} \text { a } 50 \mathrm{~m} \text { de la línea } \\
\text { de costa. }\end{array}$ \\
\hline & $\begin{array}{l}\text { En zonas de } \\
\text { mareas }\end{array}$ & & M4 & $\begin{array}{l}\text { Elementos de estructuras marinas } \\
\text { situadas en la zona de mareas y } \\
\text { salpique. }\end{array}$ \\
\hline \multirow{2}{*}{$\begin{array}{l}\text { Concreto con } \\
\text { cloruros de } \\
\text { origen } \\
\text { diferente al } \\
\text { medio marino }\end{array}$} & $\begin{array}{c}\text { Concreto } \\
\text { reforzado o } \\
\text { presforzado } \\
\text { expuesto a la } \\
\text { incorporación de } \\
\text { ion cloruro desde } \\
\text { su fabricación }\end{array}$ & & $\mathrm{Cl1}$ & $\begin{array}{l}\text { Concreto producido con materiales } \\
\text { que contengan contaminación de ión } \\
\text { cloruro soluble en el agua }<0,06 \% \text {, } \\
\text { respecto al consumo de material } \\
\text { cementante. }\end{array}$ \\
\hline & $\begin{array}{c}\text { Concreto } \\
\text { reforzado o } \\
\text { presforzado } \\
\text { expuesto a una } \\
\text { fuente externa de } \\
\text { cloruros }\end{array}$ & & $\mathrm{Cl} 2$ & $\begin{array}{l}\text { Concreto expuesto a humedad y una } \\
\text { fuente externa de cloruros. }\end{array}$ \\
\hline
\end{tabular}




\begin{tabular}{|c|c|c|c|c|}
\hline \multirow{4}{*}{$\begin{array}{l}\text { Industrial/ } \\
\text { Agresividad } \\
\text { Química }\end{array}$} & Baja & \multirow{4}{*}{ 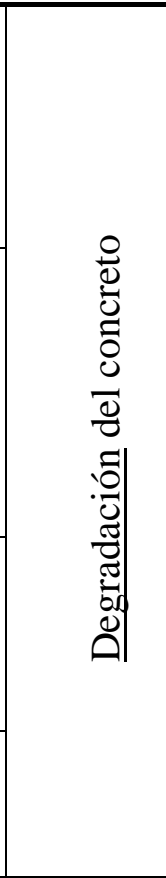 } & Q1 & $\begin{array}{l}\text { Elementos situados en ambientes con } \\
\text { contenidos de sustancias químicas } \\
\text { capaces de provocar la degradación } \\
\text { del concreto con velocidad lenta } \\
\text { (véase tabla 2). }\end{array}$ \\
\hline & Moderada & & Q2 & $\begin{array}{l}\text { Elementos en contacto con el agua de } \\
\text { mar y/o situados en ambiente } \\
\text { moderado con contenidos de } \\
\text { sustancias químicas capaces de } \\
\text { provocar la degradación del concreto } \\
\text { con velocidad media (véase tabla 2). }\end{array}$ \\
\hline & Severa & & Q3 & $\begin{array}{l}\text { Elementos expuestos a degradación } \\
\text { alta del concreto. Instalaciones } \\
\text { industriales con sustancias de alta } \\
\text { agresividad (véase tabla 2). }\end{array}$ \\
\hline & Muy severa & & Q4 & $\begin{array}{l}\text { Concreto expuesto a agresividad } \\
\text { química muy alta de sólidos, líquidos } \\
\text { y gases (véase tabla 2). }\end{array}$ \\
\hline $\begin{array}{c}\text { Clase } \\
\text { (Ambiente de } \\
\text { exposición) }\end{array}$ & $\begin{array}{c}\text { Subclase } \\
\text { (Condición de } \\
\text { exposición) } \\
\end{array}$ & $\begin{array}{l}\text { Tipo de } \\
\text { proceso }\end{array}$ & $\begin{array}{l}\text { Designación } \\
\text { (Clasificación) }\end{array}$ & Descripción \\
\hline \multirow[b]{2}{*}{$\begin{array}{c}\text { Congelamiento } \\
\text { y deshielo }\end{array}$} & $\begin{array}{c}\text { Limitada } \\
\text { exposición al agua }\end{array}$ & \multirow{2}{*}{ 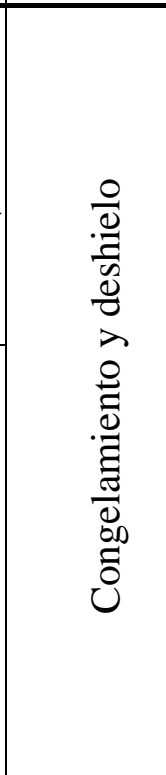 } & $\mathrm{F} 1$ & $\begin{array}{l}\text { Elementos situados en contacto } \\
\text { limitado al agua, o zonas con } \\
\text { humedad relativa media ambiental en } \\
\text { invierno menores al } 50 \% \text { y que } \\
\text { tengan una probabilidad anual } \\
\text { superior al } 50 \% \text { de alcanzar } \\
\text { temperaturas por debajo de }-5{ }^{\circ} \mathrm{C} \text {. }\end{array}$ \\
\hline & $\begin{array}{l}\text { Exposición } \\
\text { frecuente al agua } \\
\text { y sustancias } \\
\text { descongelantes }\end{array}$ & & $\mathrm{F} 2$ & $\begin{array}{l}\text { Elementos situados en contacto } \\
\text { frecuente al agua, o zonas con } \\
\text { humedad relativa media ambiental en } \\
\text { invierno mayores al } 50 \% \text { y que } \\
\text { tengan una probabilidad anual } \\
\text { superior al } 50 \% \text { de alcanzar } \\
\text { temperaturas por debajo de }-5{ }^{\circ} \mathrm{C} \text { y en } \\
\text { contacto con sustancias } \\
\text { descongelantes. }\end{array}$ \\
\hline Desgaste & $\begin{array}{l}\text { Moderado a } \\
\text { Severo }\end{array}$ & 异: & $\mathrm{D}$ & $\begin{array}{l}\text { Abrasión, cavitación. Elementos } \\
\text { sometidos a desgaste superficial. } \\
\text { Elementos de estructuras hidráulicas } \\
\text { en los que la cota piezométrica pueda } \\
\text { descender por debajo de la presión de } \\
\text { vapor de agua. }\end{array}$ \\
\hline \multicolumn{5}{|c|}{$\begin{array}{l}\text { Donde: } \\
\text { C: Ataque por carbonatación } \\
\text { M: Ataque por ambiente marino } \\
\text { Q: Ataque químico } \\
\text { F: Congelamiento y deshielo } \\
\text { D: Daño mecánico } \\
\end{array}$} \\
\hline
\end{tabular}


Tabla 2. Condiciones de exposición Industrial y agresividad química

\begin{tabular}{|c|c|c|}
\hline $\begin{array}{l}\text { Designación } \\
\text { (Clasificación) }\end{array}$ & \multicolumn{2}{|l|}{ Condiciones ambientales } \\
\hline Q1 & 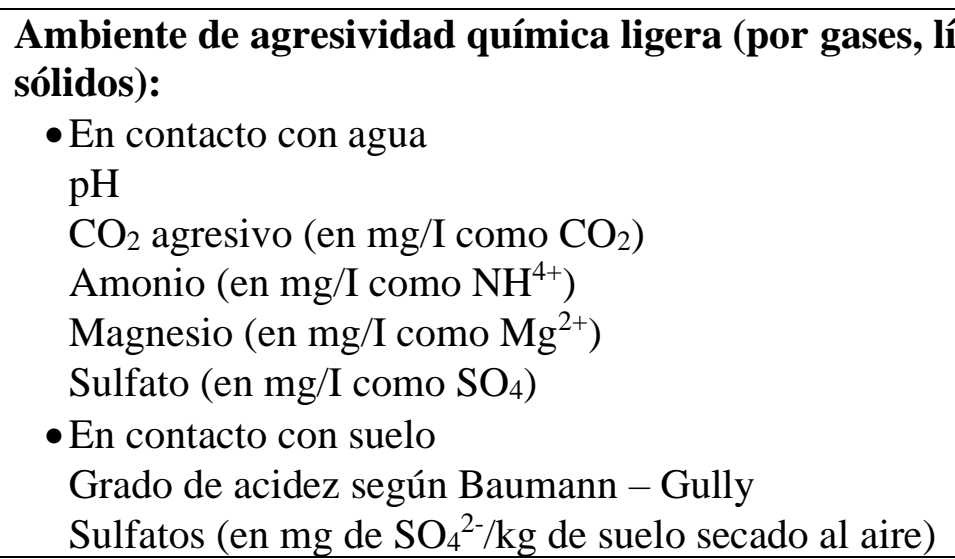 & $\begin{array}{l}\text { uidos o } \\
6,9-5,6 \\
15-30 \\
15-30 \\
100-300 \\
200-600 \\
\text { Mayor a } 20 \\
2000-6000\end{array}$ \\
\hline Q2 & 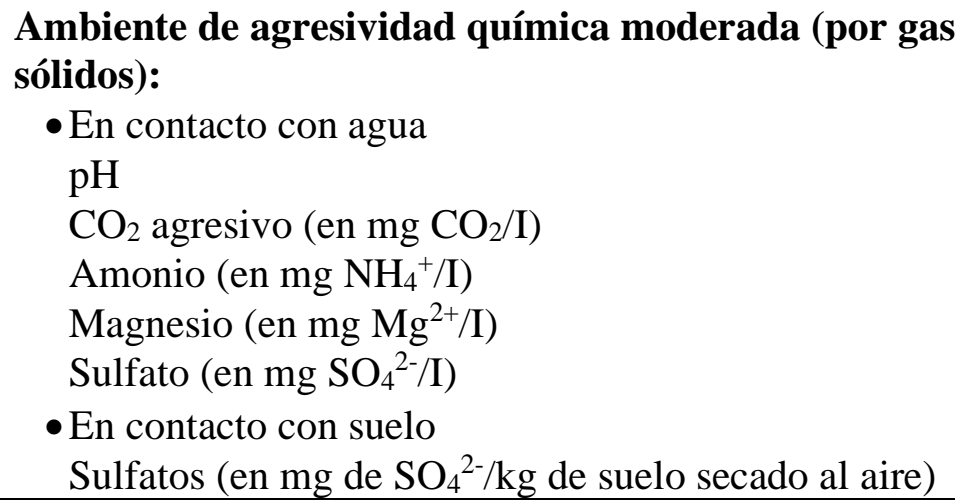 & $\begin{array}{l}\text {, líquidos o } \\
5,5-4,6 \\
31-60 \\
31-60 \\
301-1500 \\
601-3000 \\
6000-12000\end{array}$ \\
\hline Q3 & 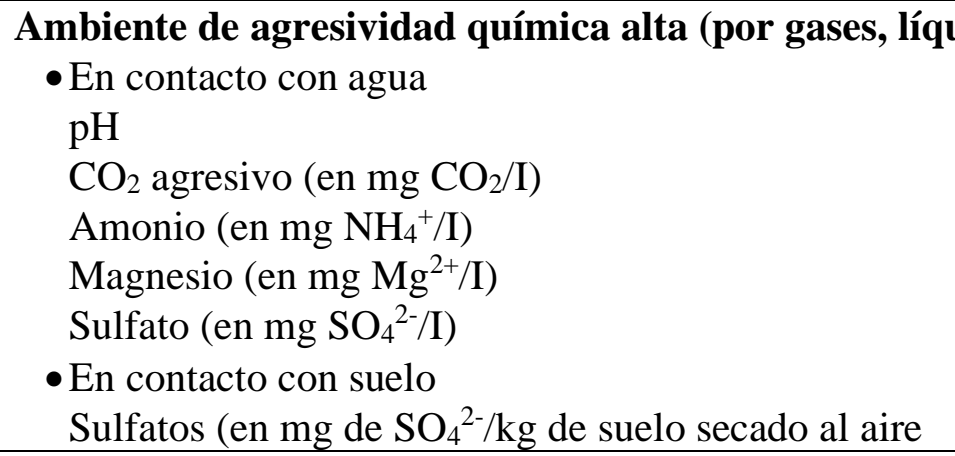 & $\begin{array}{l}\text { dos o sólidos): } \\
4,5-4,0 \\
61-100 \\
61-100 \\
1501-3000 \\
3001-6000 \\
>1200\end{array}$ \\
\hline Q4 & $\begin{array}{l}\text { Ambiente de agresividad química muy alta (por gase } \\
\text { sólidos): } \\
\text { En contacto con agua } \\
\text { pH } \\
\quad \mathrm{CO}_{2} \text { agresivo }\left(\mathrm{en} \mathrm{mg} / \mathrm{I} \text { como } \mathrm{CO}_{2}\right) \\
\quad \text { Amonio }\left(\mathrm{en} \mathrm{mg} / \mathrm{I} \mathrm{como} \mathrm{NH}^{4+}\right) \\
\quad \text { Magnesio }\left(\mathrm{en} \mathrm{mg} / \mathrm{I} \mathrm{como} \mathrm{Mg}^{2+}\right) \\
\quad \text { Sulfato }\left(\mathrm{en} \mathrm{mg} / \mathrm{I} \text { como } \mathrm{SO}_{4}\right)\end{array}$ & $\begin{array}{l}\text { líquidos o } \\
\\
<4 \\
>100 \\
>100 \\
>3000 \\
>6000\end{array}$ \\
\hline
\end{tabular}




\subsubsection{Requisitos de durabilidad}

La selección de las materias primas y el diseño de la mezcla de concreto con criterios de durabilidad deben hacerse siempre a partir de las características ambientales de exposición o de servicio de la estructura. La Tabla 3 muestra las recomendaciones generales que debe de cumplir la mezcla de diseño de concreto para cumplir el desempeño propuesto, que corresponde a la resistividad eléctrica húmeda. Los valores de resistividad eléctrica húmeda y recubrimiento mínimo propuestos en la Tabla 3 son para que elementos estructurales de concreto puedan alcanzar vidas de servicio entre 80 y 100 años. En caso de que el diseñador o dueño de la estructura quisiera modificar la vida de servicio de su estructura de concreto a valores menores, podría disminuir los valores de resistividad eléctrica húmeda de la Tabla 3.

Se plantean limitaciones a la cantidad mínima de cemento CPO y relación a/c máxima, de tal manera se obtenga la resistividad eléctrica húmeda indicada en la Tabla 3 . Se permiten modificaciones a estas recomendaciones de cantidad de cemento CPO, tipo de cemento (CPC, CPP, etc.), colocar adiciones minerales (ceniza volante, metacaolin, microsílica, etc.) en remplazo del cemento y relación a/c siempre y cuando se cumplan los valores de resistividad eléctrica húmeda propuestos para cada ambiente de exposición indicados en la Tabla 3.

\subsubsection{Requisitos de dosificación y comportamiento del concreto}

Para conseguir una durabilidad adecuada del concreto se deben cumplir los requisitos siguientes:

a) Requisitos generales:

- Relación a/mc máxima, según lo indicado en 3.2.3.2 ( $\mathrm{mc}=$ material cementante) y Tabla 3 .
- Contenido mínimo de cemento, según lo indicado en 3.2.3.2 y Tabla 3.

b) Requisitos adicionales:

- Contenido mínimo de aire incluido, en su caso, según lo indicado en 3.2.3.3 y Tabla 3 .

- Uso de cemento resistente a los sulfatos, en su caso, según lo indicado en 3.2.3.5.

- Resistencia a la erosión, en su caso, según lo indicado en 3.2.3.6.

- Resistencia a las reacciones álcaliagregado, en su caso, según lo indicado en 3.2.3.7.

\subsubsection{Limitaciones a los contenidos de agua y de cemento}

En función de las clases de exposición (véase Tablas 1 y 2) a las que vaya a estar expuesto el concreto, se deben cumplir las especificaciones indicadas en la Tabla 3.

En el caso de que el tipo de ambiente incluya una o más clases específicas de exposición, se fija, para cada parámetro, el criterio más exigente de entre los establecidos para las clases en cuestión.

\subsubsection{Permeabilidad del concreto al agua}

Una comprobación experimental de una estructura porosa de concreto con baja permeabilidad para el ambiente en el que va a estar ubicado puede realizarse verificando la permeabilidad del concreto al agua, mediante el método de determinación de la profundidad de penetración de agua o sortividad, esta comprobación se debe realizar para cualquier clase específica de exposición ambiental. 
Tabla 3 - Requisitos de durabilidad según la clase de exposición

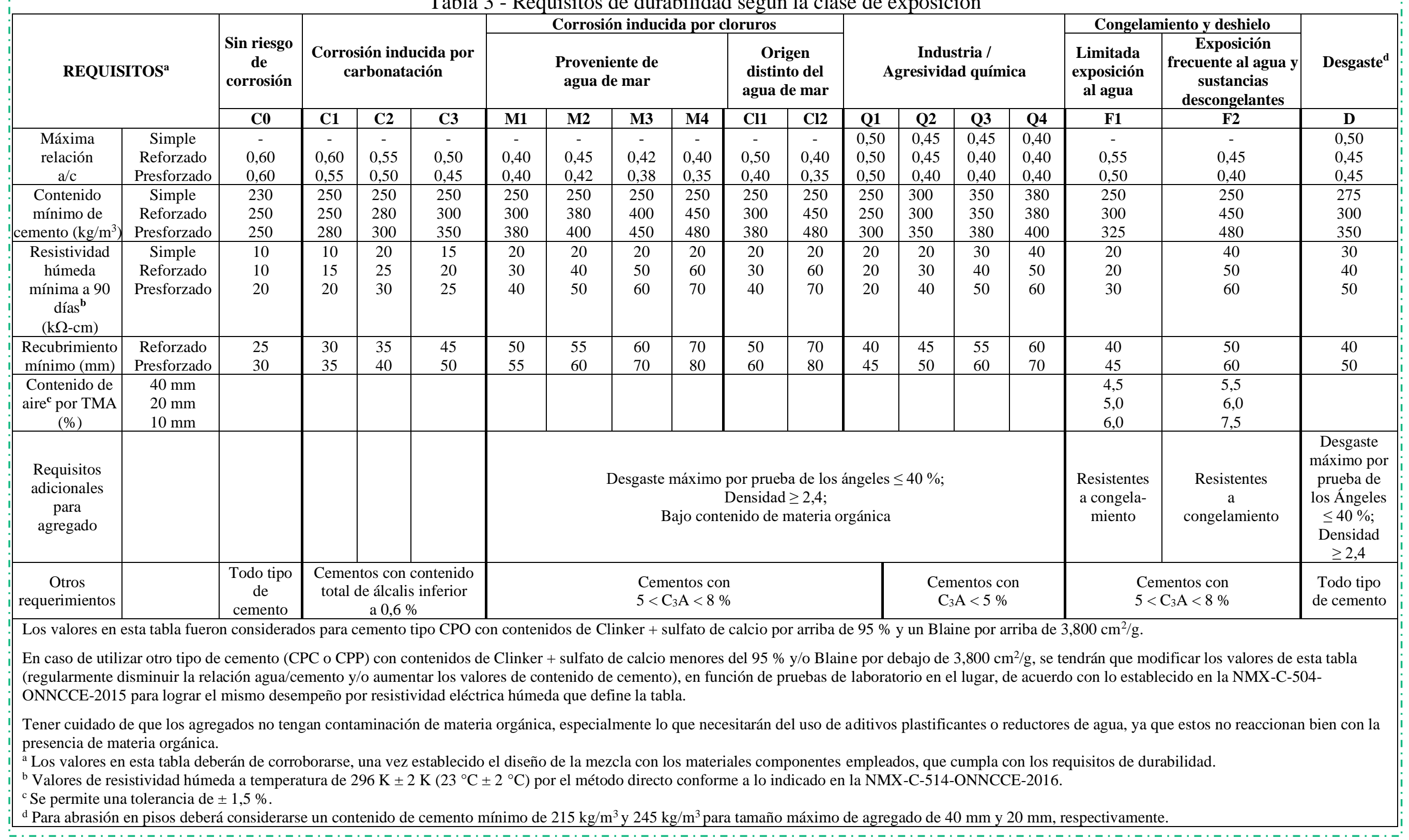


Un concreto se considera con baja permeabilidad al agua si los resultados del ensayo de penetración de agua, a una edad no menor de 28 días de fabricación, y la permeabilidad según los requerimientos del proyecto, cumplan simultáneamente con lo indicado en la Tabla 4

Tabla 4. Requisitos en los ensayos de penetración de agua

\begin{tabular}{|c|c|c|}
\hline $\begin{array}{c}\text { Clase de } \\
\text { exposición } \\
\text { ambiental }\end{array}$ & $\begin{array}{c}\text { Especificación } \\
\text { para la } \\
\text { altura máxima }\end{array}$ & $\begin{array}{c}\text { Especificación } \\
\text { para la } \\
\text { altura media }\end{array}$ \\
\hline $\mathrm{C}$ & $50 \mathrm{~mm}$ & $\leq 30 \mathrm{~mm}$ \\
\hline $\begin{array}{c}\mathrm{M}, \mathrm{Cl}, \mathrm{Q} \text { y } \\
\mathrm{F}\end{array}$ & $30 \mathrm{~mm}$ & $\leq 20 \mathrm{~mm}$ \\
\hline
\end{tabular}

\subsubsection{Resistencia del concreto frente} a condiciones de congelamiento $y$ deshielo del agua

Cuando un concreto esté sometido a una clase de exposición $\mathrm{F}$, debe introducirse un contenido mínimo de aire, de acuerdo con lo indicado en la Tabla 3.

\subsubsection{Resistencia del concreto frente al ataque por sulfatos}

En el caso particular de existencia de sulfatos en el medio, el cemento debe poseer la característica adicional de resistencia a los sulfatos (RS) y lo indicado en la clasificación de exposición a acciones de deterioro del concreto de acuerdo con lo indicado en la Tabla 3.

\subsubsection{Resistencia del concreto frente a la erosión}

Cuando un concreto vaya a estar sometido a erosión, se deben adoptar las siguientes medidas:

- Contenido mínimo de cemento y relación máxima a/mc, conforme a lo indicado en la Tabla 3.

- En el agregado fino, el contenido mínimo de partículas silíceas debe ser del $25 \%$.

- El agregado grueso debe tener un coeficiente de desgaste Los Ángeles inferior a 30.

- Curado prolongado, con duración al menos $50 \%$ superior al que se aplica para otras condiciones de exposición recomendadas para climas caliente o frio.

\subsubsection{Resistencia frente a la reactividad álcali-agregado}

Las reacciones álcali-agregado se pueden producir cuando concurren simultáneamente la existencia de un ambiente húmedo, la presencia de un alto contenido de álcalis en el cemento y la utilización de agregados que contengan componentes reactivos.

Para prevenir las reacciones álcali-agregado, se deben adoptar una de las siguientes medidas:

a) Empleo de agregados no reactivos

b) Empleo de la masa de cemento. de cementos con un contenido de álcalis, expresados como óxido de sodio equivalente $\left(0,658 \mathrm{~K}_{2} \mathrm{O}+\mathrm{Na}_{2} \mathrm{O}\right)$ inferior al $0,60 \%$

En el caso de no ser posible la utilización de materias primas que cumplan los requisitos anteriores, se debe realizar un estudio experimental específico sobre la conveniencia de adoptar una de las siguientes medidas:

a) Empleo de cementos con adiciones, salvo las de material muy fino (filler) calizo,

b) Empleo de adiciones al concreto En estos casos, puede estudiarse también la conveniencia de adoptar un método de protección adicional por impermeabilización superficial, para eliminar o disminuir el ingreso de agua al concreto.

\subsubsection{Recubrimiento de concreto}

El recubrimiento de concreto se define como el grosor de la capa de concreto que queda entre la armadura (incluyendo cercos y estribos) y la superficie del concreto exterior. Para los efectos de esta recomendación técnica, se define como recubrimiento mínimo de una armadura pasiva aquel que debe cumplirse en cualquier punto de la misma. Para garantizar estos valores mínimos, en el proyecto debe prescribirse un valor nominal del recubrimiento rnom, definido como:

$$
\text { rnom }=\text { rmín }+\Delta \mathrm{r}
$$

donde:

rnom: Recubrimiento nominal

rmín: Recubrimiento mínimo 
$\Delta \mathrm{r}$ : Margen de recubrimiento, en función del nivel de control de ejecución, y cuyo valor será $0 \mathrm{~mm}$ en elementos prefabricados con control intenso de ejecución $5 \mathrm{~mm}$ en el caso de elementos ejecutados in situ con nivel intenso de control de ejecución, y $10 \mathrm{~mm}$ en el resto de los casos.

El recubrimiento nominal es el valor que debe reflejarse en los planos, y que sirve para definir los separadores. El recubrimiento mínimo es el valor que se debe garantizar en cualquier punto del elemento y que es objeto de control.

En los casos particulares de atmósfera fuertemente agresiva o especiales riesgos de incendio, los recubrimientos indicados en la presente recomendación técnica deben ser mayores a criterio del perito en durabilidad.

\subsection{Etapa 2. Preparación para la vida de servicio, con criterios de desempeño (construcción y supervisión)}

\subsubsection{Generalidades}

La mayoría de los problemas de durabilidad se presentan durante la fase de proyecto, sin embargo, la fase de ejecución es crítica por la cantidad de omisiones que hay a las condiciones dictadas por el proyecto. Durante esta etapa deben cuidarse detalles como: uso de materiales adecuados y cumplimiento de especificaciones de construcción (espesores de recubrimiento, tipo de cemento y dosificación de la mezcla, curado, descimbrado, utilización correcta de aceros y recubrimientos especiales, etc.). Esta etapa, como su nombre lo indica, es una preparación para la vida de servicio de la estructura, por lo que la supervisión es clave para garantizar el éxito de esta fase.

\subsubsection{Calidad del concreto}

Esta es una propiedad que se relaciona con la resistencia mecánica del material, sin embargo, es la que más se descuida en términos de durabilidad. La calidad del concreto se vigila desde la dosificación en planta, pero su transporte, colocación y consolidación en obra son sumamente importantes, ya que pueden generarse problemas de segregación y sangrado que pueden comprometer desde la función estructural hasta la de durabilidad de la estructura.

\subsubsection{Transporte}

\subsection{Requisitos}

El transporte debe satisfacer los siguientes requisitos: ser suficientemente rápido para evitar pérdida de revenimiento antes de ser colocado y suficientemente eficaz para evitar que haya segregación, perdida de mortero y lechada.

\subsection{Medios empleados}

Existen diversos medios y equipos para transportar concreto y para la elección del más apropiado se requiere tomar en cuenta los siguientes aspectos: volumen de concreto a transportar, distancias mínimas y máximas, consistencia del concreto (revenimiento), tamaño máximo del agregado en la mezcla, accesibilidad para colocar el concreto dentro de las cimbras y el tiempo disponible para realizar esta operación.

Los medios de transporte más empleados son los siguientes:

a) Carretillas y vagonetas, manuales o mecanizadas. Para mover volúmenes reducidos en distancias cortas, se requiere utilizar ruedas neumáticas y habilitar vías de tránsito. La distancia máxima de entrega para el equipo mecanizado es de $120 \mathrm{~m}$ y para equipos manuales de $60 \mathrm{~m}$,

b) Camiones de caja fija con o sin agitador. El tiempo de entrega es de 30 min a 45 min, deben usarse cubiertas protectoras y jamás agregar agua en la caja de camión. No se deben transportar mezclas con revenimiento superior a 7 $\mathrm{cm}$ en este tipo de vehículo,

c) Camiones con tambor giratorio (camiones mezcladores). No operan cuando las mezclas tienen relaciones agua/material cementante muy bajas.

d) Bandas transportadoras. Son excelentes con mezclas plásticas (revenimiento de $6 \mathrm{~cm}$ a $8 \mathrm{~cm}$ ) pero como son equipos especializados, se 
necesita consultar la información técnica del fabricante.

e) Bombas neumáticas o de pistones. $\mathrm{Su}$ desempeño es satisfactorio con mezclas cohesivas con revenimiento entre $9 \mathrm{~cm}$ y $15 \mathrm{~cm}$.

Nota 3.3.2.1.2.: Información complementaria sobre equipos de transporte, puede encontrarse en el informe de los Comités ACl-304. 304-2R y 304-4R.

\subsubsection{Colocación}

La colocación incluye las operaciones necesarias para introducir el concreto en las cimbras que le dan forma, evitando la segregación y su desperdicio (merma).

\subsection{Requisitos}

a) No se debe colocar concreto que se encuentra segregado.

b) Debe evitarse depositar el concreto en las cimbras con impacto, ya que se propicia la segregación.

c) En la colocación del concreto, la altura máxima en caída libre, desde el extremo de descarga del canalón, banda transportadora, tubería de bomba u otro dispositivo debe ser como máximo de $1,5 \mathrm{~m}$, excepto cuando se usen elementos amortiguadores de la caída.

d) Debe evitarse el desplazamiento horizontal del concreto dentro del área de colocación.

e) Se debe evitar la formación de juntas frías entre dos capas sucesivas de concreto. Para concreto estructural, es necesario que el espesor de las capas horizontales no exceda de $50 \mathrm{~cm}$ y que, durante el vibrado de la capa superior, el vibrador penetre en la capa colocada previamente.

f) Es recomendable el uso de un embudo de longitud aproximada de $60 \mathrm{~cm}$ para lograr que el concreto baje verticalmente.

Nota 3.3.2.2.1.: Información complementaria sobre la colocación del concreto, puede encontrarse en el informe del Comité ACI-304

\subsubsection{Compactación}

\subsection{Medios empleados}

La compactación es la operación que permite hacer fluir al concreto recién colocado dentro de las cimbras para llenar todo el espacio confinado por las mismas y darles la máxima compacidad posible. Para logrado, se requiere someterlo a vibraciones de frecuencias superiores a 3000 vibraciones por minuto (vpm). Los equipos vibradores pueden ser de inmersión, externos o de superficie, accionados por medio de electricidad, aceite a presión o gasolina. No es recomendable el acomodo del concreto por medio de picado.

\subsection{Requisitos}

a) El vibrador debe introducirse rápidamente y extraerse del concreto con lentitud, en dirección completamente vertical y a distancias regulares.

b) El tiempo que el vibrador debe permanecer dentro del concreto en cada inserción depende de su consistencia; debe comenzar a extraerse en el momento en que la superficie del concreto adquiere brillo por efecto del flujo de lechada.

c) Evítese sobrevibrar el concreto, o desplazarlo lateralmente mediante la aplicación inclinada del vibrador, porque se produce segregación

Nota 3.3.2.3.2.: Información complementaria sobre la colocación y acomodo del concreto, puede encontrarse en el Informe del Comité ACl-309 y ACI-30S-1R.

\subsubsection{Curado}

Durante el fraguado y primer período de endurecimiento del concreto, se debe asegurar el mantenimiento de la humedad del mismo mediante un curado adecuado. Éste se prolonga durante el plazo necesario en función del tipo y clase del cemento, de la temperatura y la humedad relativa ambiental, insolación, velocidad del viento, etc. El curado puede realizarse manteniendo húmedas las superficies de los elementos de concreto, mediante riego directo que no produzca deslavado. El curado por aportación de humedad se puede sustituir por la protección de las superficies mediante recubrimientos plásticos, membranas de curado $\mathrm{u}$ otros tratamientos adecuados, siempre que tales métodos, especialmente en el caso de masas secas, ofrezcan las garantías que se estimen necesarias para lograr, durante el primer período de endurecimiento, la retención de la humedad inicial de la masa, y no contengan sustancias nocivas para el concreto. $\mathrm{Si}$ el curado se realiza empleando técnicas 
especiales (curado al vapor, por ejemplo) se procede con apego a las normas de buena práctica propias de dichas técnicas.

El concreto debe mantenerse en un ambiente húmedo por lo menos durante catorce días en el caso de cemento ordinario y siete días si se empleó cemento de alta resistencia inicial. Estos lapsos deben aumentarse si la temperatura desciende a menos de $278 \mathrm{~K}\left(5^{\circ} \mathrm{C}\right)$.

Para acelerar ganancia de resistencia mecánica y reducir el tiempo de curado, puede usarse el curado con vapor a alta presión, vapor a presión atmosférica, calor y humedad, o algún otro proceso que sea aceptado. El proceso de curado que se aplique debe producir concreto cuya durabilidad sea por lo menos equivalente a la obtenida con curado en ambiente húmedo prescrito en el párrafo anterior.

El curado es uno de los requerimientos críticos durante la fabricación del concreto para lograr el adecuado avance de las reacciones de hidratación del cemento, que conduce a la densificación (reducción de la porosidad) de la matriz. Un curado deficiente deriva en una cantidad mayor de poros más grandes, en perjuicio de la durabilidad. Por ello, en esta etapa, la presencia de agua y el cumplimiento de las especificaciones de curado son vitales para garantizar la vida de servicio de proyecto.

\subsubsection{Resistencia a la compresión}

El ensayo de resistencia a la compresión en esta etapa da una idea representativa de la calidad inmediata y futura del concreto.

\subsubsection{Recubrimiento de concreto}

Antes de llevar a cabo el colado es importante tener en cuenta el recubrimiento de la armadura, ya que este desempeña dos papeles importantes a lo largo de la vida de servicio del elemento. Primero proporciona una barrera física al acero contra la entrada de los agentes agresivos evitando así la activación del acero; segundo desde el punto de vista estructural disminuiría o aumentaría la sección transversal del elemento. Para supervisar que el recubrimiento sea del espesor correcto podemos con ayuda de un flexómetro convencional medir desde el paño de la armadura hasta el paño interno de la cimbra, es necesario cuidar que esta distancia no se vea alterada al momento de colocar el concreto, esto puede evitarse colocando espaciadores. Si el acero cambia de posición es necesario hacer el ajuste a su posición inicial antes de que el concreto fragüe.

Los requerimientos mínimos de concreto dependen de las condiciones ambientales y de si el acero actúa como refuerzo normal o presforzado, los requisitos se indican en la tabla 3.

Los valores mínimos de recubrimiento deben incluir tolerancias para asegurar su valor bajo cualquier circunstancia. El valor de la tolerancia depende del control de la calidad de la construcción. Con un adecuado control de la calidad y un curado eficiente, la tolerancia es de $5 \mathrm{~mm}$; sin control de la calidad debe incrementarse a $10 \mathrm{~mm}$ y si el curado es inadecuado a $20 \mathrm{~mm}$.

\subsubsection{Dosificación de mezcla}

\subsubsection{Material Cementante}

La dosificación del material cementante se debe hacer siempre en masa.

\subsubsection{Agregados}

La dosificación de la arena y la grava puede hacerse en masa, mediante peso directo de las cantidades requeridas, o bien por volumen, mediante la medición de los volúmenes correspondientes a los pesos requeridos, utilizando recipientes rígidos estancos, de forma regular y capacidad bien definida $y$ conocida, los cuales deben aforarse periódicamente. Cualquier recipiente que sea aforable y mantenga sus dimensiones bajo uso rudo puede emplearse, debe mantenerse un registro de las determinaciones de aforo de los recipientes.

Nota 3.3.4.2.: Para mantener un volumen consistente de la arena, debe determinarse el abundamiento de ésta por humedad y realizar una corrección en la dosificación antes de emplearse

\subsubsection{Agua}

La dosificación del agua de mezclado puede hacerse en masa, mediante peso directo de la cantidad requerida, o bien por medición del volumen equivalente $(1 \mathrm{~kg}=1$ litro, aproximadamente) en un recipiente rígido, estanco y de capacidad aforada. 


\subsubsection{Aditivos}

El comportamiento de los concretos con diversos tipos de materiales cementantes está definido dentro de un esquema relativamente rígido, ya que no siempre pueden satisfacer todos los requerimientos de los procesos constructivos modernos, en consecuencia, existen múltiples casos en que la única alternativa de solución técnica y eficiente es el uso de aditivos.

Cuando se permite el uso de aditivos, estos deben dosificarse en masa si son sólidos, o bien pueden dosificarse en masa o por volumen si son líquidos. En cualquier caso, la dosificación se reporta con respecto a la masa del material cementante. Para su dosificación, tanto en masa como por volumen, debe contarse con dispositivos de medición que una precisión de + $3 \%$ con respecto a las cantidades requeridas.

Nota 3.3.4.4.: Información complementaria sobre la dosificación del concreto en masa o en volumen, puede encontrarse en el informe ACI-204 y la norma ASTM-C 685. Información complementaria acerca de los distintos aditivos véase ASTM C494.

\subsubsection{Varillas de acero}

$\mathrm{El}$ agrietamiento es inevitable en las estructuras de concreto en las zonas de máximo momento, ya que al tomar el acero la carga de tensión el concreto se agrieta. Estas grietas no son indicio de deterioro de las condiciones de servicio de la estructura, siempre que el ancho de la grieta no sea excesivo (véase 3.7.2.). La cantidad de acero de refuerzo debe ser la suficiente para controlar el ancho del agrietamiento en las áreas donde ocurre la tensión.

Un excesivo espaciamiento del acero de refuerzo conduce a la aparición de grietas irregulares entre el refuerzo; por lo tanto, el diámetro y espaciamiento de las varillas de refuerzo debe limitarse de acuerdo con el diseño estructural.

En zonas donde se concentran esfuerzos de tensión por cambios volumétricos o empotramientos deben evitarse desde el diseño de la estructura, deben evitarse estas concentraciones de esfuerzos de tensión permitiendo el libre movimiento como suele suceder mediante juntas de expansión en edificios y puentes. Es necesaria una cantidad mínima de refuerzo en aquellas partes de la estructura en donde los cambios de temperatura, retracción u otras acciones den como resultado la aparición de altos esfuerzos de tensión altos. La supervisión en esta etapa se puede hacer mediante una inspección visual y un buen control del armado de la estructura, los requisitos necesarios son que las varillas cumplan con el diámetro establecido, el espaciamiento entre las mismas, el espaciamiento entre el elemento y el paño interior de la cimbra, el correcto anclaje a la cimbra de la estructura, que las varillas estén en buen estado, etc.

\subsubsection{Anclaje y doblez}

Mediante una inspección visual puede realizarse la supervisión del armado de la estructura, esta inspección se puede realizar con ayuda de un flexómetro convencional y una bitácora en la cual se irán levantando los datos de la construcción de los elementos, es requerido realizar la supervisión con ayuda del proyecto.

\subsubsection{Grado de permeabilidad (porosidad)}

Para supervisar este criterio en esta etapa es requerido verificar que se tenga un proporcionamiento de concreto que produzca baja permeabilidad para tener una protección eficaz al acero, la supervisión se debe hacer principalmente en factores como la relación agua/material cementante, el tipo de material cementante, la compactación, la eficiencia del curado y el espesor de recubrimiento de concreto. Para verificar el cumplimiento de los criterios de calidad, es recomendable hacer pruebas con los concretos antes de construir. La reducción de la permeabilidad limita la velocidad de carbonatación desde la superficie.

\subsubsection{Contenido de cloruros}

Para prevenir la corrosión del acero de refuerzo es necesario que todos los elementos que intervienen en la mezcla, pero en especial el agua tenga el mínimo contenido de contaminantes. En el caso de cloruros, el agua de amasado debe contener menos de 250 partes por millón (ppm), y por lo tanto los agregados como la dosificación de la mezcla deben contener como máximo los valores contemplados en la tabla 5 . 
Tabla 5 Contenidos máximos de cloruros en los componentes de la mezcla

\begin{tabular}{|c|c|}
\hline Componente & Concentración \\
\hline Cemento & $100 \mathrm{ppm}^{*}$ \\
\hline Agregado fino & $0,04 \mathrm{ppa}^{* *}$ \\
\hline Agregado grueso & $0,04 \mathrm{ppa}^{* *}$ \\
\hline Agua & $250 \mathrm{ppm}^{*}$ \\
\hline $\begin{array}{l}\text { * ppm (partes por millón). } \\
* * \text { ppa (por ciento por peso de agregado). }\end{array}$ \\
\hline
\end{tabular}

Para la protección contra la corrosión del acero de refuerzo en el concreto, las concentraciones máximas de iones cloruro solubles en agua en concreto endurecido a edades que van de 28 a 42 días, provenientes de los ingredientes, incluyendo agua, agregados, materiales cementantes y aditivos, no deben exceder los límites de la Tabla 6.

\section{Tabla 6. Limites}

\begin{tabular}{|l|c|}
\hline \multicolumn{1}{|c|}{ Tipo de elemento } & $\begin{array}{l}\text { Contenido máximo de iones cloruro } \\
\left(\mathbf{C l}^{-}\right) \text {solubles en agua en el concreto, } \\
\text { porcentaje en peso de cemento (ppc) }\end{array}$ \\
\hline Concreto presforzado & 0,06 \\
\hline $\begin{array}{l}\text { Concreto reforzado que en servicio estará } \\
\text { expuesto a cloruros }\end{array}$ & 0,15 \\
\hline $\begin{array}{l}\text { Concreto reforzado que en servicio estará seco o } \\
\text { protegido contra la humedad }\end{array}$ & 1,00 \\
\hline Otras construcciones de concreto reforzado & 0,30 \\
\hline
\end{tabular}

\subsubsection{Desniveles}

Se requiere que antes de construir se revise el proyecto en el cual se definen los esquemas estructurales, las formas geométricas y los detalles que sean compatibles con la consecución de una adecuada durabilidad de la estructura.

Se debe evitar el empleo de diseños estructurales que sean especialmente sensibles frente a la acción del agua y, en la medida de lo posible, reducir al mínimo el contacto directo entre ésta y el concreto, excepto para estructuras diseñadas para estar en contacto con el agua. Se requiere prever la construcción de los sistemas adecuados para la conducción y drenaje (conducciones, etc.) del agua. Se debe poner atención en procurar evitar el paso de agua sobre las zonas de juntas y sellados.

Es necesario prever los sistemas adecuados para evitar la existencia de superficies sometidas a salpicaduras o encharcamiento de agua. Cuando la estructura presente secciones con aligeramientos $\mathrm{u}$ oquedades internas, se debe disponer de los sistemas necesarios para su ventilación y drenaje.

Salvo en obras de pequeña importancia, debe preverse en la medida de lo posible, el acceso a todos los elementos de la estructura, estudiando la conveniencia de disponer sistemas específicos que faciliten la inspección y el mantenimiento durante la etapa 4 (véase 4.5).

\subsubsection{Drenajes}

La supervisión del drenaje en esta etapa puede hacerse con una simple inspección visual, mediante el escurrimiento de agua evitando el estancamiento del agua, es recomendable tener una velocidad superior a $0,5 \mathrm{~m} / \mathrm{s}$ y menor a 4 $\mathrm{m} / \mathrm{s}$. El deterioro de las tuberías de concreto debido a los compuestos de ácidos sulfhídrico o sulfúrico, originado por la actividad bacteriana en sistemas de drenaje, puede disminuirse minimizando la turbulencia en las tuberías, en esta forma se reduce la liberación de dichos compuestos, reduciendo así los cultivos de bacterias en el interior de las tuberías. Una buena ventilación de los drenajes es un medio eficiente para prevenir este proceso.

\subsubsection{Pares galvánicos}

Cuando 2 metales de distinto potencial electroquímico están en contacto o se encuentran en el mismo electrolito, ocurre la corrosión galvánica. La corrosión es estimulada por la diferencia de potencial que existe entre los 2 metales, el material más noble actúa como un cátodo donde algunas especies oxidantes son reducidas, el metal más activo el cual es el que 
se corroe, actúa como el ánodo.

Por tal motivo es importante tener en cuenta a la hora de construir evitar el contacto directo o indirecto de materiales de distinto potencial electroquímico, esto puede ocurrir tanto en instalaciones aéreas como en inmersas en concreto. La correcta supervisión en esta etapa ayudará a concebir una estructura con la vida de servicio deseada (véase 3.3.11.1. y 3.3.11.2.). A continuación, se presenta la tabla 7 con los potenciales estándar de algunos metales usados en la construcción.

\begin{tabular}{|c|c|c|}
\hline Rango & $\begin{array}{c}\text { Equilibrio } \\
\text { Metal - Ion metálico } \\
\text { (Actividad unitaria) }\end{array}$ & $\begin{array}{l}\text { Potencial de reducción de electrodo } \\
\text { vs electrodo normal de Hidrogeno a } \\
\qquad 25^{\circ} \mathrm{C}, \mathrm{V}\end{array}$ \\
\hline Noble & $\mathrm{Au}-\mathrm{Au}^{+3}$ & $+1,498$ \\
\hline & $\mathrm{Pt}-\mathrm{Pt}^{+2}$ & $+1,2$ \\
\hline & $\mathrm{Pd}-\mathrm{Pd}^{+2}$ & $+0,987$ \\
\hline & $\mathrm{Ag}-\mathrm{Ag}^{+}$ & $+0,799$ \\
\hline & $\mathrm{Hg}-\mathrm{Hg}_{2}+2$ & $+0,788$ \\
\hline & $\mathrm{Cu}-\mathrm{Cu}^{+2}$ & $+0,337$ \\
\hline & $\mathrm{H}_{2}-\mathrm{H}^{+}$ & 0,000 \\
\hline & $\mathrm{Pb}-\mathrm{Pb}^{+2}$ & $-0,126$ \\
\hline & $\mathrm{Sn}-\mathrm{Sn}^{+2}$ & $-0,136$ \\
\hline & $\mathrm{Ni}-\mathrm{Ni}^{+2}$ & $-0,250$ \\
\hline & $\mathrm{Co}-\mathrm{Co}^{+2}$ & $-0,277$ \\
\hline & $\mathrm{Cd}-\mathrm{Cd}^{+2}$ & $-0,403$ \\
\hline & $\mathrm{Fe}-\mathrm{Fe}^{+2}$ & $-0,440$ \\
\hline & $\mathrm{Cr}-\mathrm{Cr}^{+3}$ & $-0,744$ \\
\hline & $\mathrm{Zn}-\mathrm{Zn}^{+2}$ & $-0,763$ \\
\hline & $\mathrm{Al}-\mathrm{Al}^{+2}$ & $-1,662$ \\
\hline & $\mathrm{Mg}-\mathrm{Mg}^{+2}$ & $-2,363$ \\
\hline & $\mathrm{Na}-\mathrm{Na}^{+}$ & $-2,714$ \\
\hline Activo & $\mathrm{K}-\mathrm{K}^{+}$ & $-2,925$ \\
\hline
\end{tabular}

\subsubsection{Pares galvánicos en instalaciones aéreas}

Cuando se está construyendo, las instalaciones aéreas son más fáciles de supervisar con respecto a los pares galvánicos, ya que las primeras se encuentran expuestas, y una simple inspección visual permite reconocer los segundos. Cuando exista un par galvánico, y el proyecto así lo permita, es necesario evitar el contacto eléctrico. Esto se logra a través de materiales aislantes disponibles por ejemplo como cintas, rondanas, sujetadores, cables, etc. Un ejemplo claro pueden ser los conductos de ventilación, ya que comúnmente son utilizados elementos de aluminio para el soporte y tornillos de acero para la fijación.

Cuando el proyecto no permita hacer modificaciones, para separar un elemento de otro, es necesario colocar un material aislante que impida el contacto eléctrico entre los mismos.

\subsubsection{Pares galvánicos inmersos en concreto}

Antes de realizar el colado del elemento que en su interior tendrá instalaciones, es necesario supervisar minuciosamente la no existencia de pares galvánicos, un ejemplo de esto son las armaduras de acero y los conductos de aluminio. Una vez hecho el colado se dificulta la tarea de aislamiento eléctrico que implicaría romper y reparar. $\mathrm{Al}$ igual que las instalaciones aéreas y por presentar un área pequeña se recomienda la utilización de aislantes.

\subsubsection{Impermeabilización}

El concreto en si es un material permeable, esto se debe a los diferentes tipos de poros presentes 
en la estructura, entre los que pueden considerarse como críticos aquellos que dejan los agregados no son llenados completamente por los productos de la hidratación del material cementante, aunado a esto el agua utilizada se evapora cuando el proceso curado es inadecuado.

Al momento de colar, es necesario tener en cuenta los siguientes criterios que proporcionaran una baja permeabilidad al elemento.

a) Emplear mezclas de baja relación agua/material cementante ya que los concretos más resistentes son los más impermeables. Esto se debe a la formación de matrices densificadas y de baja porosidad.

b) Tener una granulometría con el mínimo posible de vacíos.

c) Compactar el concreto con la ayuda de un vibrador, el cual ayuda a expulsar las burbujas de aire. Es importante hacerlo con cuidado para evitar que el vibrador altere.

\subsubsection{Separación entre separadores}

Todo el acero de refuerzo debe mantenerse firmemente en su lugar antes y durante el colado del concreto por medio de espaciadores o silletas individuales o continuas que pueden ser pequeños bloques de concreto o soportes metálicos o de plástico para evitar cualquier desplazamiento durante la construcción y asegurar que el acero quede a la distancia de diseño desde la cimbra. Aun con los valores de las tolerancias añadidos a los valores del recubrimiento de concreto indicados, los valores mínimos especificados pueden asegurarse si se colocan silletas adecuadas con separaciones suficientemente pequeñas.

En la tabla siguiente se encuentran las separaciones máximas para las silletas individuales en función del diámetro nominal del refuerzo. En las tablas 8, 9 y 10, que se encuentran más adelante, se dan las separaciones para el acero longitudinal, así como el tipo de espaciador y la posición. Los parámetros de estas tablas se definen en la figura 2.

Tabla 8. Separación so entre silletas individuales

\begin{tabular}{|c|c|}
\hline $\begin{array}{c}\text { Diámetro nominal } \\
\text { del refuerzo }(\mathbf{m m})\end{array}$ & $\begin{array}{c}\text { Separación entre } \\
\text { silletas, so } \mathbf{( m m})\end{array}$ \\
\hline$<8$ & 400 \\
\hline $8-14$ & 500 \\
\hline$>14$ & 700 \\
\hline
\end{tabular}

Tabla 9. Separación $\mathrm{s}_{1}$ entre silletas individuales (losas y muros)

\begin{tabular}{|c|c|}
\hline $\begin{array}{c}\text { Diámetro nominal } \\
\text { del refuerzo }(\mathbf{m m})\end{array}$ & $\begin{array}{c}\text { Separación entre } \\
\text { silletas, so } \mathbf{( m m})\end{array}$ \\
\hline$<10$ & 500 \\
\hline $12-20$ & 1000 \\
\hline$>20$ & 1250 \\
\hline
\end{tabular}

Tabla 10. Separación $s_{2}$ entre silletas individuales (trabes)

\begin{tabular}{|c|c|c|}
\hline $\begin{array}{c}\text { Tipo de } \\
\text { silleta }\end{array}$ & $\begin{array}{c}\text { Posición } \\
\text { horizontal } \\
\text { (losas) }\end{array}$ & $\begin{array}{c}\text { Posición } \\
\text { vertical } \\
\text { (muros) }\end{array}$ \\
\hline Silleta simple & $\mathrm{s}_{0}$ & $1.5 \mathrm{~s}_{0}$ \\
\hline $\begin{array}{c}\text { Silleta } \\
\text { continua }\end{array}$ & $1.5 \mathrm{~s}_{0}$ & $2.0 \mathrm{~s}_{0}$ \\
\hline
\end{tabular}
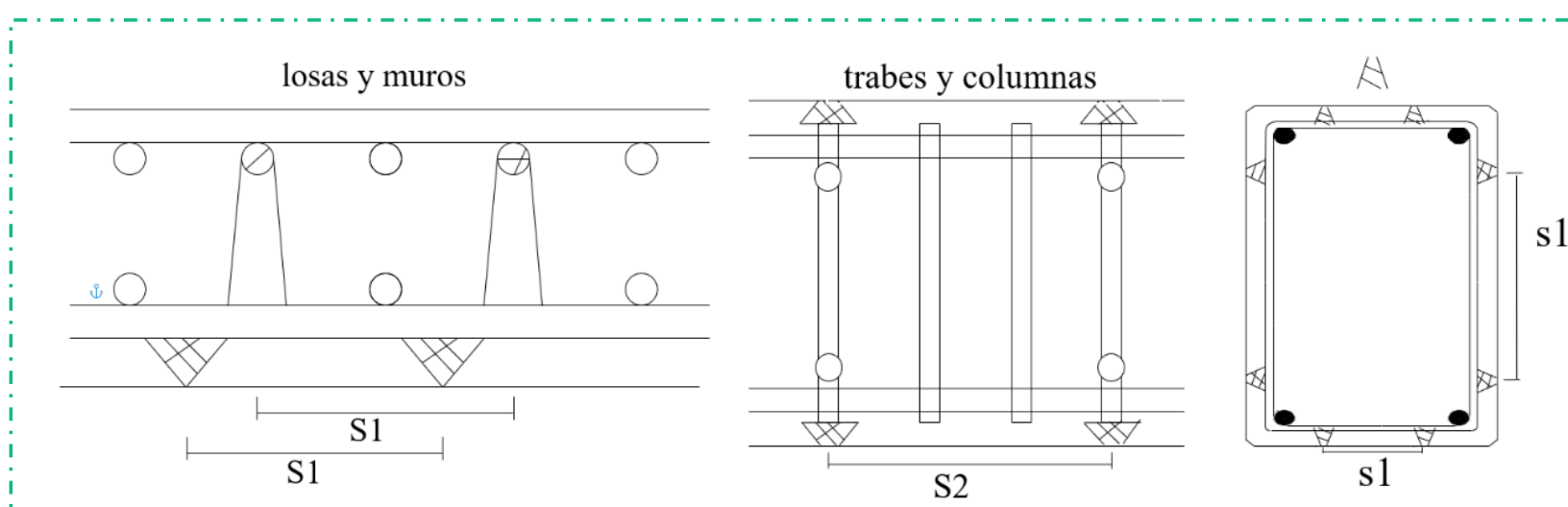

Figura 2. Tipos de separadores 


\subsubsection{Supervisión durante la construcción}

En la parte de supervisión y control de la calidad de concretos durables se debe dar un seguimiento cercano al proceso de dosificación, fabricación, transporte, colocación, consolidación, curado y recubrimiento. Para determinar que el concreto ya colocado y endurecido, cumpla con los requisitos de desempeño por durabilidad proyectados se deben extraer testigos de concreto en elementos estratégicos. La verificación debe incluir el verificar que el concreto en el elemento estructural cumpla el desempeño solicitado, principalmente la resistividad eléctrica húmeda y/o la absorción capilar. De la misma manera debe verificarse, no solo la calidad del concreto, sino también la cantidad que está funcionando como la barrera física del acero de refuerzo o presfuerzo que proporcionará la vida de servicio de diseño. Para ello se realizan mediciones de espesor de recubrimiento de los elementos de concreto con acero para que corrobore que el recubrimiento mínimo estipulado (Tabla 3) o en el diseño ejecutivo del proyecto, se cumplan. De esta manera, se tendrá la certeza de que el elemento de concreto fabricado, calidad y cantidad del concreto cumpla con los criterios de durabilidad diseñados.

\subsection{Etapa 3. Inicio de la vida de servicio (puesta en servicio e inicio de vida de útil y planeación de mantenimiento)}

\subsubsection{Generalidades}

Esta etapa es un punto en el tiempo, pero es de suma importancia para la vida de servicio de la estructura. En esta parte es donde la obra es recibida por el usuario y puesta en servicio. Cualquier problema o error constructivo no detectado y corregido en esta etapa tiende a ocasionar inconvenientes mayores por la dificultad que suponen las acciones correctivas cuando la estructura está en uso. Antes de firmar el acta de entrega, se deben verificar detalles críticos en la estructura, ya sea con métodos convencionales o modernos, o ya sea también con técnicas no destructivas (TND) o destructivas (TD).

\subsubsection{Verificación de recubrimiento de concreto}

Antes de recibir la estructura es necesario realizar la verificación del recubrimiento de concreto para constatar que cumpla con lo especificado en el proyecto, esto es posible realizarlo con un pachómetro comercial convencional.

\subsubsection{Dosificación de mezcla}

Una vez construido un elemento o estructura de concreto es complicado verificar su dosificación. Sin embargo, esto puede hacerse a través de testigos de concreto que son extraídos a determinadas edades y cuyos resultados de resistencia a la compresión o tensión indirecta podrían ser indicativo de la dosificación utilizada. Existen procedimientos estándar que ayudan a determinar la relación agua/material cementante utilizada y la cantidad de cemento en el mezclado para poder verificar si se cumplieron las especificaciones del proyecto.

\subsubsection{Varillas de acero}

En esta etapa pueden verificarse la cantidad y diámetro de barras utilizadas para contrastarlas con las especificadas en el proyecto. Para ello se utiliza un pachómetro comercial convencional.

\subsubsection{Anclaje y doblez}

Aunque la verificación de anclajes y dobleces es complicada después de la construcción, ésta puede hacerse con el pachómetro comercial y mediante ensayos selectivos. El ensayo selectivo puede consistir en ubicar elementos representativos de la estructura, los cuales no sean los más desfavorables, esto a fin de no provocar daños en la capacidad portante de la 
estructura; una vez ubicado el acero con el pachómetro se procede a realizar la demolición de parte del elemento para descubrir el acero interno. El procedimiento debe ser rápido para posteriormente resanar el elemento.

\subsubsection{Grado de permeabilidad (porosidad)}

Para verificar la permeabilidad o porosidad efectiva en esta etapa se usa la técnica establecida en la absorción capilar en concreto hidráulico.

\subsubsection{Contenido de cloruros}

La cantidad de cloruros en un elemento construido es muy importante para determinar posibles intervenciones en el futuro, pero también para controlar el ingreso de éstos en una forma económica. En esta etapa se deben extraer testigos y analizar los perfiles iniciales de cloruros desde el exterior hasta el nivel del estribo. Con este dato se debe hacer un seguimiento como parte de un mantenimiento preventivo, y predecir avances de aquellos. Esta toma de datos puede indicar también si hay cantidades anormales de inicio, producto del uso indebido de algún material o que estuviese contaminado.

\subsubsection{Desniveles}

Los desniveles en esta etapa se revisan con niveles y con pruebas de agua para verificar que no existan estancamientos. Su corrección es importante para promover la durabilidad del elemento, especialmente si está ubicado en zonas marinas. A continuación, se propone un sistema de corrección práctico cuando en esta etapa los desniveles verificados no cumplen con lo estipulado en el proyecto.

\subsubsection{Sobrecapas}

Es un método de reparación de estructuras mediante la colocación de un material superpuesto que permite resolver una variedad de problemas en la superficie de concreto.

Se utiliza para mejorar los niveles y la superficie de rodadura, aumentar la capacidad de carga para proteger el concreto de ambientes agresivos y finalmente resolver problemas de deterioro de la superficie de concreto.

\subsection{Uso}

Se emplea en reparaciones superficiales generalizadas, en losas o plataformas de concreto, de puentes y pavimentos en general.

\subsection{Características del material}

a) La técnica permite el uso de diferentes materiales y de diversos espesores. Los rangos de espesores más usados son de $4 \mathrm{~mm}$ a $8 \mathrm{~mm}$.

b) Los materiales comúnmente usados son concretos de cemento Portland con una relación baja de agua/material cementante y concretos de cemento Portland modificados con látex $\mathrm{o}$ microsílice.

c) Se permiten espesores menores de 3 $\mathrm{mm}$ cuando se aplican morteros poliméricos o morteros poliméricos modificados. El más común es el epóxico el cual se combina con arena graduada para formar un mortero.

\subsection{Colocación del material}

a) Previo a la colocación del material se debe hacer un tratamiento de la superficie que promueva la adherencia con el concreto existente. Esta se consigue a través de un picado, escarificado o cincelado.

b) La colocación del material de reparación se hace en conformidad con las especificaciones del fabricante, dando especial atención a las técnicas de vaciado para prevenir problemas de fisuramiento, contracción plástica, segregación, falta de adherencia y falta de consolidación.

c) La mayoría de las aplicaciones no requieren refuerzo adicional, más se usan fibras para mejorar sus propiedades como resistencia al impacto y disminuir la contracción plástica.

\subsection{Equipo}

a) Martillo neumático

b) Fresa escarificadora (milling machine) 


\subsubsection{Drenajes}

Los drenajes en esta etapa deben mostrar una funcionalidad completa, sin embargo, debe verificarse la no obstrucción de sus sistemas. Esto garantizará la durabilidad al canalizar correctamente los líquidos y con ello evitar que sustancias agresivas permeen a zonas donde hay acero.

\subsubsection{Pares galvánicos}

La unión accidental o intencional de metales de diferente aleación provenientes de refuerzos, tuberías y otras instalaciones puede desembocar en corrosión galvánica. Esto es complicado de reparar en etapas avanzadas y es costoso. Como parte de las acciones en esta etapa, deben verificarse este tipo de uniones y en donde las exista, debe garantizarse su aislamiento eléctrico. Como parte del plan de mantenimiento periódico, debe verificarse el estado del aislamiento.

\subsubsection{Pares galvánicos en instalaciones aéreas}

En este tipo de situaciones, se requiere un método de reparación mucho más económico y sencillo que los pares galvánicos inmersos en concreto, basta con colocar un aislante entre los dos metales y/o tratar de separarlos por otros medios para que no exista el diferencial de potencial.

\subsubsection{Pares galvánicos inmersos en concreto}

Cuando se realiza la supervisión de la estructura y se detecta la presencia de un par galvánico es necesario intervenir el elemento antes de que éste presente síntomas de corrosión. Dado que en esta etapa podría ser imposible aislar mecánicamente el par galvánico, una posibilidad que dependería principalmente de la economía es el uso de la protección catódica, la cual tiene como función llevar las armaduras embebidas en el concreto a un potencial de valor tal que la corrosión no pueda tener lugar. Se puede llevar a cabo la protección mediante dos medios:

a) Ánodo de sacrificio o protección galvánica. Se conecta la armadura a los llamados ánodos de sacrificio, que son materiales que poseen mayor tendencia a corroerse que el acero del concreto, como magnesio, zinc o aluminio, o aleaciones basadas en estos materiales; estos materiales de potencial menor obligan a la armadura a comportarse como cátodo. La reacción química entre el ambiente y la pieza sacrificada impide la reacción entre el ambiente y la pieza útil.

En medio acuoso, basta con atornillar el ánodo de sacrificio a la pieza que se debe proteger; al aire, hay que recubrir totalmente la pieza a proteger; en estructuras de concreto, estos ánodos deben ser compatibles con el material cementante para evitar el deterioro de aquellos debido a reacciones de auto-corrosión.

b) Protección por corriente impresa. Se mantiene el mismo principio fundamental, pero debido a las limitaciones que presenta el método de ánodo de sacrificio en cuanto a material, costo y diferencia de potencial, se ha enfocado en el flujo de corriente requerido, el cual se origina en una fuente de corriente generadora continua regulable o, simplemente se hace uso de rectificadores, que alimentados por corriente alterna ofrecen una corriente eléctrica continua apta para la protección de la estructura.

La corriente externa disponible es impresa en el circuito formado por la estructura a proteger y la cama anódica. La dispersión de la corriente eléctrica en el electrólito se efectúa mediante la ayuda de ánodos inertes cuyas características y aplicación dependen del electrólito.

\subsubsection{Impermeabilización}

El estado de la impermeabilización en esta etapa debe ser íntegro y no dejar resquicios por donde la humedad $\mathrm{u}$ otros agentes agresivos puedan ocasionar problemas patológicos. Las pruebas con agua pueden indicar los riesgos de filtración, lo mismo que las uniones y las grietas del material de impermeabilización.

Nota 3.4.11. Información complementaria sobre el grado de permeabilidad de un elemento puede encontrarse en la UNE-EN 12390-8:2009

\subsubsection{Planeación de mantenimiento}

Se provee el plan de mantenimiento preventivo/correctivo en función de la agresividad del medio e importancia de la 
estructura. Este plan debe considerar que los elementos secundarios de una estructura puedan tener vida de servicio diferentes (apoyo de neoprenos, juntas de dilatación, etc.), por lo que deberán existir guías técnicas para su restitución de tal manera que la vida de servicio de la estructura se alcance.

El plan de mantenimiento debe tomar en cuenta lo siguiente:

a) Verificación y corrección por defectos de construcción como drenes, desagües, pares galvánicos y espacios

b) confinados que puedan dar lugar a corrosión, acumulación de basura o productos de lluvia ácida en zonas críticas, posibles fugas de aguas negras o jabonosas, desprendimiento de recubrimientos y pinturas, filtraciones inesperadas, etc.

c) Verificación del impacto de la agresividad del ambiente sobre la estructura a través de mediciones electroquímicas, con sensores embebidos o no, de la resistividad del concreto, el potencial de corrosión, la velocidad de corrosión, etc.

d) Verificación del impacto de la agresividad del ambiente sobre la estructura a través de mediciones de carbonatación, contenido de cloruros, reacciones a los sulfatos y álcaliagregado. Corrección de predicciones y actualización del plan de mantenimiento para ejercer acciones correctivas cuando sea necesario.

\subsection{Etapa 4. Vida de servicio (Etapa de propagación 1, mantenimiento preventivo o no, entrada de agresivos)}

\subsubsection{Generalidades}

Esta etapa es donde inicia la propagación de daños, es vital para que la estructura alcance la vida de servicio de proyecto. Una creencia popular y errónea es que en las etapas iniciales la estructura no mostrará patología alguna y de ahí que confianza se evitan las inspecciones de la estructura durante períodos largos de tiempo. El inicio de esta etapa debe tener un monitoreo adecuado para poder plantear, eventualmente, cualquier acción para enmendar el plan de mantenimiento preventivo.

El seguimiento de todos estos parámetros debe hacerse continuamente. Cuando las mediciones no se hayan realizado desde el principio, deben hacerse en esta etapa y es necesaria la actualización del plan de mantenimiento preventivo incluyendo las acciones propias de la etapa siguiente.

\subsubsection{Criterios de durabilidad}

En esta etapa el criterio principal es el preventivo, es decir, ejercer cualquier acción necesaria para prevenir el daño que ocasiona el ingreso de agentes agresivos a la pasta de cemento hidratada del concreto y al refuerzo (dióxido de carbono y cloruros para fines de esta recomendación técnica). La aplicación de un criterio de durabilidad es variada y depende no sólo de una especificación por desempeño, sino de la experiencia del evaluador. En esta etapa los criterios de durabilidad a seguir son:

a) Potencial de corrosión del refuerzo

b) Velocidad de corrosión del refuerzo

c) Resistividad del concreto

d) Resistencia a la compresión

e) Resistencia a la tensión por compresión diametral

f) Determinación del índice de rebote por medio de la Esclerometría

g) Absorción por capilaridad

\subsubsection{Corrosión por cloruros en concreto reforzado expuesto a ambiente tropical marino}

Esta etapa contempla la vigilancia del ingreso de cloruros al concreto y los parámetros de corrosión a través de un plan de inspección y mantenimiento preventivo. El plan debe incluir la verificación de estos valores cuando menos cada año y ejercer acciones preventivas cuando los indicadores se encuentren a un $75 \%$ de alcanzar la despasivación o umbral de cloruros (ver tablas A1-A4). Al detectarse esto, debe planearse $y$ efectuarse un mantenimiento preventivo a más tardar un año después. Con 
esta medida se logra una actuación previa a la despasivación o al ingreso de contenidos críticos de cloruros al concreto. Entre las medidas preventivas se encuentra la aplicación de revestimientos o cualquier otra medida que disminuya la acción agresiva.

\subsubsection{Corrosión por carbonatación en concreto reforzado expuesto a ambientes urbanos}

Esta etapa contempla la vigilancia del ingreso de dióxido de carbono al concreto y los parámetros de corrosión a través de un plan de inspección y mantenimiento preventivo. El plan debe incluir la verificación de estos valores cuando menos cada año y ejercer acciones preventivas cuando los indicadores se encuentren a un $75 \%$ de alcanzar la despasivación (ver los criterios en apéndice A). Al detectarse esto, debe planearse y efectuarse un mantenimiento preventivo cuando mucho un año después. Con esta medida se logra una actuación previa a la despasivación o al ingreso de dióxido de carbono al concreto. Entre las medidas preventivas se encuentra la aplicación de revestimientos o cualquier otra medida que disminuya la acción agresiva.

\subsection{Etapa 5. Vida de servicio residual (Etapa de propagación 2, mantenimiento correctivo, final de vida útil)}

\subsubsection{Generalidades}

Cuando los agentes agresivos llegan al acero de refuerzo, o se han producido situaciones en el elemento o estructura que puedan empezar a comprometer su confiabilidad arquitectónica, estructural o de durabilidad, es necesario tomar acciones correctivas inmediatas. Las acciones dependerán del grado de avance y complejidad del daño, solución, la complejidad, el tiempo y el costo de la intervención. En esta etapa se considera únicamente el tipo de daño que, aunque presente, no ha mostrado manifestaciones graves. Por ejemplo, el caso de una estructura donde los cloruros han llegado al umbral para producir corrosión, pero no ha causado agrietamiento o perdida de sección severos, sino lixiviaciones que afectan la estética; otro caso podría ser por una carbonatación que haya llegado hasta la barra, pero que por lo lento de la cinética no haya producido aún desprendimientos severos, o el caso de una estructura de concreto en contacto con agua que empieza a mostrar algunas exudaciones o lixiviaciones, etc. En todos estos casos, existen soluciones para revertir el proceso de daño o al menos retrasarlo por un buen tiempo, durante el cual se recupera el desempeño mínimo de la estructura. El objetivo del plan de mantenimiento correctivo de esta etapa es alejar lo más posible la condición de daño grave o colapso parcial o total. El plan correctivo en esta etapa soluciona los $\overline{\text { problemas }} \overline{\text { principales }} \overline{\mathrm{y}}-\overline{\text { controla, }} \overline{\text { por }} \overline{-}$ un tiempo, la aparición de efectos colaterales.

\subsubsection{Especificaciones contra el ataque ambiental}

Según la definición de esta etapa, si la carbonatación ha llegado al acero de refuerzo, pero la corrosión producida aún no produce grietas ni desprendimientos severos, una especificación de uso práctico es bloquear el acceso de humedad. En este caso se puede usar un bloqueador de poros comercial. Un ejemplo sería una columna en ambiente urbano agresivo. Por otro lado, si los cloruros han llegado hasta la armadura, la habrá despasivado pero únicamente se ha producido lixiviación de productos de corrosión sin grietas: la extracción de cloruros o la disminución de la humedad disponible (siguiendo las recomendaciones del párrafo previo) pudiesen retrasar el agrietamiento y disminuir la velocidad de la reacción. Para conocer los tipos de ambientes y sus especificaciones, véase las tablas 1 y 2.

\subsubsection{Corrosión del refuerzo}

La corrosión del refuerzo puede desarrollarse rápidamente cuando se supera el umbral respectivo de carbonatación y/o cloruros, cuando esto ocurre la corrosión que se presenta es indicativa del fin de la vida de servicio y el inicio de la vida de servicio residual. Las 
acciones emprendidas al principio de esta etapa van a determinar su duración. Por ello es importante la aplicación correcta de las técnicas que se mencionan en el apartado 3.6.3.1.

\subsubsection{Técnicas de reparación y rehabilitación de estructuras de concreto en ambiente tropical marino.}

La etapa de vida de servicio residual es una de las más comunes al momento de que el propietario llama a un especialista, esto debido a que es la etapa en la que se presentan las manifestaciones de daño visuales. En esta etapa, pueden aplicarse una gran cantidad de técnicas que alarguen la duración de la primera en condiciones de operatividad satisfactoria. Algunas de ellas son la remoción electroquímica de cloruros, la re-alcalinización de concreto, la sustitución de secciones contaminadas y dañadas por medio de reparaciones selectivas, el uso de aceros especiales en zonas selectivas previo uso de las dos primeras, la aplicación de protección catódica, entre otras.

\subsection{Etapa 6. Vida residual (Cualquier mantenimiento no recupera el desempeño mínimo)}

\subsubsection{Generalidades}

Como su nombre lo indica, es vida residual y no vida de servicio residual. La diferencia fundamental estriba en que esta etapa es cuando los daños que se han presentado ya son mayores y comprometen la confiabilidad arquitectónica, estructural o de durabilidad. El tratamiento correctivo no devuelve el desempeño mínimo como en la etapa anterior, pues existen consecuencias colaterales de los problemas descritos en la etapa anterior. Por ejemplo, ya no es solo el umbral de cloruros para producir corrosión que se ha superado, sino la presencia de fuertes expansiones y agrietamientos que permiten entrada de más contaminantes y cuyo tratamiento no se puede resolver, por ejemplo, con una remoción de cloruros. Esta etapa es aquella en la que la inversión, aunque cuantiosa, puede permitir a la estructura seguir funcionando con ciertos requisitos de serviciabilidad, aunque es muy recomendable el cambio de uso pues no puede responder con la misma confiabilidad a las solicitaciones requeridas. En el momento en que los paliativos sean tanto o más costosos que hacer una estructura nueva se considera que ha iniciado la etapa 7.

Esta es la etapa en que se encuentra la mayoría de las estructuras al momento en que se busca la consultoría de un experto, debido, entre otras cosas, a la falta de conocimiento sobre el procedimiento de intervención. De aquí la dificultad para resolver los problemas y para predecir una extensión de vida de servicio. En esta etapa los pasos que hay que seguir son los siguientes:

a) Inspección detallada de la estructura. Se necesitan pruebas de carga, deflexiones, pruebas químicas, electroquímicas y del ambiente, etc.

b) Definición de un plan integral para corregir los defectos con materiales y técnicas avanzadas.

c) Implementación de un modelo que permita predecir la duración de la vida residual después de la intervención y la relación costo/beneficio mínimo antes de proceder al certificado de defunción.

d) En función del nivel de daños, proponer las zonas en las que se tiene que hacer cambios de uso de la estructura.

Es importante mencionar que muchas de las estructuras que están en esta etapa pueden tener usos significativos para la sociedad. Por ejemplo, un tanque elevado de agua, que constituye un símbolo para determinada sociedad pero que, a pesar de la reparación, no es conveniente volverlo a usar como tal, podría, por ejemplo, funcionar por más tiempo como un mirador en alguno de los niveles de su estructura, o para colocar anuncios de empresas, etc. Este es el caso también de casonas antiguas que pasan a ser parte de la decoración de un gran hotel pero que ya no reciben las solicitaciones que recibían en el pasado. 


\subsubsection{Valores máximos de la abertura de la grieta}

Las fisuras provocan efectos negativos en la armadura, lo cual permite una penetración gradual de cloruros, humedad y oxígeno.

El ancho aceptable de una grieta en un elemento depende de su función en la estructura, así como del tipo de exposición de ésta, siendo este uno de los criterios a considerar en esta etapa, así como su longitud. Un criterio práctico podría ser el de un ancho de $0.1 \mathrm{~mm}$, arriba del cual se considera en esta etapa y una longitud que no sobrepase los máximos admisibles aceptados por el código vigente. La Tabla 11 muestra anchos de grieta tolerables por durabilidad en el concreto.

Tabla 11. Ancho de grietas tolerables por durabilidad en el concreto reforzado

\begin{tabular}{|l|c|}
\hline \multicolumn{1}{|c|}{ Condición de exposición } & $\begin{array}{c}\text { Ancho de grieta tolerables por } \\
\text { durabilidad, en mm }\end{array}$ \\
\hline Aire seco, membrana protectora & 0,40 \\
\hline Humedad, aire húmedo, suelo & 0,30 \\
\hline Químicos para deshielo & 0,20 \\
\hline $\begin{array}{l}\text { Agua de mar y rociado con agua } \\
\text { de mar, mojado y secado }\end{array}$ & 0,15 \\
\hline $\begin{array}{l}\text { Estructuras que retienen el agua, } \\
\text { excluyendo tubos sin presión }\end{array}$ & 0,10 \\
\hline
\end{tabular}

Nota 3.7.2. Una grieta de $0,1 \mathrm{~mm}$ es poco visible, a menos que la superficie se moje y después se le permita secar. El valor de $0,1 \mathrm{~mm}$ es la frontera entre una fisura y una grieta

\subsubsection{Cantidad de grietas}

Otro criterio para considerar a la estructura es la cantidad de grietas, ya que el concreto debido a su fragilidad siempre contiene microfisuras las cuales al combinarse con las fisuras visibles crean una red. Una vez formada la red el mecanismo de transporte de agentes agresivos deja de ser por difusión, pasando a ser por permeabilidad en medio acuoso.
Aunque no existe un criterio universal debido a las características de cada tipo de obra en particular, se considera que, si las grietas atraviesan secciones longitudinales o transversales, éste ya es criterio suficiente para ser considerada en esta etapa.

\subsection{Etapa 7. Fin de la vida residual (Inicio del colapso parcial o total)}

\subsubsection{Generalidades}

Cuando una estructura presenta colapsos parciales y no pasa las pruebas convencionales y especializadas de confiabilidad, o más aún, cualquier intervención costará más que demolerla y hacer una nueva, o cuando el cambio de uso es muy difícil por diferentes condiciones que van desde las ambientales, sociedad o uso, entonces la estructura queda desahuciada o en desuso hasta que se procede a su demolición. Debido a que el concreto es muy noble, se tienen infinidad de obras, pero sobre todo viviendas populares en este estado. Para detectar esta etapa y proceder como corresponde hay que seguir $\overline{\text { los }}$ pasos siguientes:

a) Realizar una inspección detallada en la que se justifique con plenitud que ninguna intervención ni cambio de uso puede restablecer la funcionalidad de la estructura ni la seguridad para sus ocupantes.

b) El perito correspondiente debe expedir un certificado de inseguridad y falta de confiabilidad indicando las razones y los plazos para proceder a su demolición, debido al riesgo que constituya para sus ocupantes y la sociedad. 


\section{CRITERIOS DE EVALUACIÓN}

Durante las etapas de vida de servicio de una estructura pueden llevarse a cabo los mismos tipos de muestreo para los mismos tipos de prueba; sin embargo, la interpretación de estos será diferente en función de la edad, condiciones de uso y exposición al ambiente. El apartado 5 describe las normas o métodos para cada tipo de prueba, dígase velocidad de corrosión, contenido de cloruros, resistividad o cualquier otra de durabilidad. Sin embargo, existen criterios universales para hacer el muestreo al utilizar cualquier tipo de prueba, en términos generales el muestreo debe contemplar:

a) Un criterio para seleccionar áreas de evaluación. Por lo general debe tomarse en cuenta un área con ataque severo, otra con ataque intermedio y otra sin ataque, esto para poder generar condiciones de comparación

b) Un criterio para extraer las muestras y/o medir. En función de la edad, condiciones de uso y exposición al ambiente la toma de muestra y/o medición debe apegarse a lo establecido en su respectivo método de ensayo.

c) Un criterio de interpretación de resultados. En función de la edad, condiciones de uso y exposición al ambiente la toma de muestra y/o medición respectiva debe coadyuvar a encontrar las tendencias establecidas como hipótesis de razón de daño.

d) Un criterio de experiencia en casos similares de obras propias o de otros. Cada caso de una estructura en cuanto a problemas patológicos puede ser muy diferente dependiendo de la edad, el diseño, el tipo de problema patológico, las condiciones de exposición, los métodos previos de inspección y reparación, etc. Un mismo modelo de casa de interés social, pero construido con materiales y ambientes diferentes, puede dar lugar a problemas patológicos diferentes. El acceso a fuentes de información propias o externas (por ejemplo, revistas técnicas de patología de la construcción) permite crear y acumular experiencia que servirá invariablemente para cumplir adecuadamente con los criterios de los incisos a), b) y c) del muestreo.

\section{MÉTODOS DE ENSAYO}

Para verificar las especificaciones que se establecen en esta recomendación técnica, deben utilizarse los métodos de prueba descritos en la Tabla 12. 
Tabla 12. Métodos de ensayo o especificaciones para la durabilidad según la clase de exposición

\begin{tabular}{|c|c|}
\hline Requisito & Método de ensayo o especificaciones \\
\hline \multicolumn{2}{|c|}{ General } \\
\hline Resistencia a la compresión $\left(\mathrm{kg} / \mathrm{cm}^{2}\right)$ & $\begin{array}{l}\text { UNE-EN 12390-3:2020 } \\
\text { ISO 1920-4:2005 } \\
\text { ASTM C39/C39M - } 20 \\
\text { NMX-C-083-ONNCCE }\end{array}$ \\
\hline $\begin{array}{l}\text { Contenido mínimo de cemento en el } \\
\text { concreto, }\left(\mathrm{kg} / \mathrm{m}^{3}\right)\end{array}$ & $\begin{array}{c}\text { ASTM C1084 - } 19 \\
\text { NMX-C-154-ONNCCE-2010 }\end{array}$ \\
\hline $\begin{array}{c}\text { Contenido de aire por tamaño máximo } \\
\text { de agregado } \% \text {. Se permite una } \\
\text { tolerancia de } \pm 1.5 \%\end{array}$ & $\begin{array}{c}\text { ASTM C231 / C231M - 17a } \\
\text { ASTM C173/C173M } \\
\text { NMX-C-157-ONNCCE-2006 } \\
\text { NMX-C-162-ONNCCE-2014 } \\
\text { ISO 1920-2:2016(en) } \\
\text { UNE-EN 12350-7:2020 }\end{array}$ \\
\hline Requisitos adicionales para agregado & $\begin{array}{c}\text { ASTM C33 / C33M - 16e1 } \\
\text { NMX-C-111-ONNCCE-2018 } \\
\text { UNE-EN 12620:2003+A1:2009 }\end{array}$ \\
\hline Requisitos adicionales para cemento & $\begin{array}{c}\text { ASTM C150/C150M - 19a } \\
\text { NMX-C-414-ONNCCE-2017 } \\
\text { UNE-EN 197-1:2011 }\end{array}$ \\
\hline \multicolumn{2}{|c|}{ Ataque por exposición ambiental } \\
\hline $\mathrm{pH}$ en agua & $\begin{array}{c}\text { ASTM D1293-12 } \\
\text { NMX-C-283-ONNCCE-2017 } \\
\text { NMX-C-122-ONNCCE-2019 } \\
\text { UNE 83952:2008 }\end{array}$ \\
\hline $\mathrm{CO}_{2}$ en agua & $\begin{array}{c}\text { ASTM D513 - } 16 \\
\text { NMX-C-283-ONNCCE-2017 } \\
\text { NMX-C-122-ONNCCE-2019 }\end{array}$ \\
\hline Cloruro en el agua & $\begin{array}{c}\text { ASTM D512 - } 12 \\
\text { NMX-C-283-ONNCCE-2017 } \\
\text { NMX-C-122-ONNCCE-2019 } \\
\text { UNE 83958:2014 }\end{array}$ \\
\hline Sulfato en el agua & $\begin{array}{c}\text { ASTM D516 - } 16 \\
\text { NMX-C-283-ONNCCE-2017 } \\
\text { NMX-C-122-ONNCCE-2019 } \\
\text { UNE 83956:2008 }\end{array}$ \\
\hline Sulfatos en el suelo & $\begin{array}{c}\text { ASTM C1580-15 } \\
\text { UNE 83963:2008 }\end{array}$ \\
\hline
\end{tabular}




\subsection{Para los materiales y componentes}

Para verificar la calidad de los materiales y componentes, deben utilizarse los métodos de ensayo establecidos en la Tabla 13.

\begin{tabular}{|c|c|}
\hline $\begin{array}{l}\text { Materiales y componentes del } \\
\text { concreto }\end{array}$ & Método de ensayo y/o especificaciones \\
\hline Cemento & $\begin{array}{c}\text { ASTM C150/C150M - 19a } \\
\text { NMX-C-414-ONNCCE-2017 } \\
\text { UNE-EN 197-1:2011 }\end{array}$ \\
\hline Agregado & $\begin{array}{c}\text { ASTM C33 / C33M - 16e1 } \\
\text { NMX-C-111-ONNCCE-2018 } \\
\text { UNE-EN 12620:2003+A1:2009 }\end{array}$ \\
\hline Agua de mezclado & $\begin{array}{c}\text { ISO 12439:2010 } \\
\text { NMX-C-283-ONNCCE-2017 } \\
\text { NMX-C-122-ONNCCE-2019 } \\
\text { UNE-EN 1008:2007 }\end{array}$ \\
\hline Aditivos & $\begin{array}{c}\text { ASTM C494 / C494M - } 19 \\
\text { NMX-C-255-ONNCCE-2013 } \\
\text { ISO 19596:2017(en) } \\
\text { UNE-EN 934-1:2009 }\end{array}$ \\
\hline Adicionantes & NMX-C-146-ONNCCE-2000 \\
\hline
\end{tabular}

\subsection{Requisitos para el concreto en estado fresco}

Para verificar la calidad del concreto fresco, deben utilizarse los métodos de ensayo establecidos en la Tabla 14.

Tabla14. Concreto fresco

\begin{tabular}{|c|c|}
\hline Concreto fresco & Método de ensayo y/o especificaciones \\
\hline \multirow{2}{*}{ Revenimiento o } & ASTM C143 / C143M - 15a \\
Flujo de revenimiento & NMX-C-156-ONNCCE-2010 \\
& ISO 1920-2:2016(en) \\
UNE-EN 12350-2:2020 \\
\hline \multirow{3}{*}{ Masa unitaria y rendimiento } & ASTM C138/138M-17a \\
& NMX-C-162-ONNCCE-2014 \\
& UNE-EN 12350-6:2020 \\
\hline \multirow{2}{*}{ Temperatura del concreto } & NMX-C-435-ONNCCE-2010 \\
& ISO 1920-2:2016(en) \\
\hline \multirow{3}{*}{ Tamaño máximo del agregado } & ASSHTO T 2 \\
& NMX-C-155-ONNCCE-2014 \\
& UNE 146406:2018 \\
\hline Contenido de aire & NMX-C-157-ONNCCE-2006, \\
& NMX-C-158-ONNCCE-2006 \\
& ISO 1920-2:2016(en) \\
& UNE-EN 12350-7:2020 \\
\hline
\end{tabular}




\subsection{Requisitos para el comportamiento mecánico del concreto en estado endurecido}

Para verificar la calidad del concreto en estado endurecido, deben utilizarse los métodos de ensayo establecidos en la Tabla 15.

\begin{tabular}{|c|c|}
\hline \multicolumn{2}{|c|}{ Tabla 15. Concreto en estado endurecido } \\
\hline Concreto en estado endurecido & Método de ensayo y/o especificaciones \\
\hline Resistencia a la compresión & $\begin{array}{c}\text { ISO 1920-4:2005 } \\
\text { ASTM C39/C39M - } 20 \\
\text { NMX-C-083-ONNCCE-2014 } \\
\text { UNE-EN 12390-3:2020 }\end{array}$ \\
\hline Módulo de elasticidad & $\begin{array}{c}\text { ASTM C469 / C469M - } 14 \\
\text { NMX-C-128-ONNCCE-2019 } \\
\text { UNE-EN 13412:2008 }\end{array}$ \\
\hline Ensayo de núcleos & $\begin{array}{c}\text { NMX-C-169-ONNCCE-2009 } \\
\text { ASTM C42/C42M - 18a } \\
\text { UNE-EN 12504-1:2020 }\end{array}$ \\
\hline Variación en la longitud & $\begin{array}{c}\text { NMX-C-173-ONNCCE-2010 } \\
\text { UNE 83318:1994 }\end{array}$ \\
\hline Abrasión & $\begin{array}{c}\text { UNE-EN 14617-4:2012 } \\
\text { Véase Nota. 5.3 }\end{array}$ \\
\hline Resistencia a la tensión por flexión & $\begin{array}{c}\text { NMX-C-191-ONNCCE-2015 } \\
\text { AASHTO T 97-18 (ASTM Designation: C78/C78M-16) } \\
\text { UNE-EN 12390-5:2020 }\end{array}$ \\
\hline $\begin{array}{l}\text { Resistencia a la tensión por } \\
\text { compresión diametral }\end{array}$ & NMX-C-163-ONNCCE-2019 \\
\hline
\end{tabular}

\subsection{Durabilidad de elementos y estructuras de concreto}

Tabla 16. Durabilidad

\begin{tabular}{|c|c|}
\hline Permeabilidad al ion cloruro & $\begin{array}{c}\text { NMX-C-155-ONNCCE-2014 } \\
\text { UNE-EN 13396:2005 }\end{array}$ \\
\hline $\begin{array}{c}\text { Potenciales de corrosión del acero de refuerzo sin } \\
\text { revestir, embebido en concreto }\end{array}$ & $\begin{array}{c}\text { NMX-C-495-ONNCCE-2014 } \\
\text { UNE 112083:2010 }\end{array}$ \\
\hline Velocidad de corrosión en campo & NMX-C-501-ONNCCE-2014 \\
\hline Absorción capilar & $\begin{array}{c}\text { NMX-C-504-ONNCCE-2014 } \\
\text { UNE 83982:2008 }\end{array}$ \\
\hline $\begin{array}{c}\text { Inspección preliminar de daños en estructuras de } \\
\text { concreto hidráulico con criterios de durabilidad }\end{array}$ & $\begin{array}{c}\text { NMX-C-505-ONNCCE-2014 } \\
\text { Resistividad eléctrica del concreto hidráulico }\end{array}$ \\
\hline $\begin{array}{c}\text { NMX-C-514-ONNCCE-2016 } \\
\text { UNE 83988-1:2008 }\end{array}$ \\
\hline $\begin{array}{c}\text { Ueterminación de la profundidad de carbonatación en } \\
\text { concreto hidráulico }\end{array}$ & $\begin{array}{c}\text { NMX-C-515-ONNCCE-2015 } \\
\text { UNE-EN 14630:2007 }\end{array}$ \\
\hline Procedimiento de preparación y limpieza de \\
superficies para reparación & $\begin{array}{c}\text { NMX-C-518-ONNCCE-2015 } \\
\text { UNE 83702:1994 IN }\end{array}$ \\
\hline Concentración de cloruros solubles en agua y ácido & $\begin{array}{c}\text { NMX-C-523-ONNCCE-2016 } \\
\text { UNE-EN 14629:2007 }\end{array}$ \\
\hline
\end{tabular}




\section{BIBLIOGRAFÍA}

1. ACI 204 Design and construction practices to mitigate cracking.

2. ACI 304 Guide for measuring, mixing, transporting, and placing concrete.

3. ACI 305 Hot weather concreting.

4. ACI 309 Guide for consolidation of concrete.

5. ACI 318 Building Code Requirements for Structural Concrete.

6. ASSHTO T 2 - Sampling of Aggregates.

7. AASHTO T 97-18 Standard Method of Test for Flexural Strength of Concrete (Using Simple Beam with Third-Point Loading) (ASTM Designation: C78/C78M-16)

8. ASTM C33 / C33M - 16e1 Standard Specification for Concrete Aggregates

9. ASTM C39/C39M - 20 Standard Test Method for Compressive Strength of Cylindrical Concrete Specimens

10. ASTM C42/C42M - 18a Standard Test Method for Obtaining and Testing Drilled Cores and Sawed Beams of Concrete

11. ASTM C138/138M-17a Standard Test Method for Density (Unit Weight), Yield, and Air Content (Gravimetric) of Concrete

12. ASTM C143 / C143M - 15a- Standard Test Method for Slump of Hydraulic-Cement Concrete

13. ASTM C150/C150M - 19a Standard Specification for Portland Cement

14. ASTM C173/C173M, Standard Test Method for Air Content of Freshly Mixed Concrete by the Volumetric Method

15. ASTM C231 / C231M - 17a Standard Test Method for Air Content of Freshly Mixed Concrete by the Pressure Method

16. ASTM C469 / C469M - 14 Standard Test Method for Static Modulus of Elasticity and Poisson's Ratio of Concrete in Compression

17. ASTM C494 / C494M - 19 Standard Specification for Chemical Admixtures for Concrete

18. ASTM-C-685/C685M-17 Standard specification for concrete made by volumetric batching and continuous mixing.

19. ASTM C876 - 15 Standard Test Method for Corrosion Potentials of Uncoated Reinforcing Steel in Concrete

20. ASTM C1084 - 19 Standard Test Method for Portland-Cement Content of Hardened HydraulicCement Concrete 
21. ASTM C1580 - 15 Standard Test Method for Water-Soluble Sulfate in Soil

22. ASTM D512 - 12 Standard Test Methods for Chloride Ion In Water

23. ASTM D513 - 16 Standard Test Methods for Total and Dissolved Carbon Dioxide in Water

24. ASTM D516 - 16 Standard Test Method for Sulfate Ion in Water

25. ASTM D1293-12 Standard test methods for $\mathrm{pH}$ of water

26. ASTM-E-337-90 Test method for measuring humidity with a psychrometer (the measurement of wet - bulbanddry - bulb temperature)

27. Instrucción Española de Hormigón Estructural (EHE-08).

28. ISO 1920-2:2016(en) Testing of concrete — Part 2: Properties of fresh concrete

29. ISO 1920-4:2005 - Testing of concrete - Part 4: Strength of hardened concrete

30. ISO 4316:1977(en) Surface active agents - Determination of $\mathrm{pH}$ of aqueous solutions Potentiometric method

31. ISO 12439:2010 Mixing water for concrete

32. ISO 19596:2017(en), Admixtures for concrete

33. NMX-C-083-ONNCCE-2014 Industria de la Construcción - Concreto - Determinación de la resistencia a la compresión de especímenes - Método de ensayo.

34. NMX-C-111-ONNCCE-2018, Industria de la construcción - Agregados para concreto hidráulico Especificaciones y métodos de ensayo

35. NMX-C-122-ONNCCE-2019, Industria de la construcción-Agua para concreto-Especificaciones

36. NMX-C-128-ONNCCE-2019, Industria de la construcción-Concreto sometido a compresiónDeterminación de módulo de elasticidad estático y relación de poisson-Método de ensayo

37. NMX-C-154-ONNCCE-2010 Industria de la construcción - Concreto hidráulico - Determinación del contenido de cemento en concreto endurecido

38. NMX-C-155-ONNCCE-2014, Industria de la construcción - Concreto hidráulico - Dosificado en masa especificaciones y métodos de ensayo

39. NMX-C-156-ONNCCE-2010 Industria de la construcción - Concreto hidráulico - Determinación del revenimiento en el concreto Fresco

40. NMX-C-157-ONNCCE-2006, Industria de la construcción - Concreto - Determinación del contenido de aire del concreto fresco por el método de presión

41. NMX-C-158-ONNCCE-2006, Industria de la construcción - Concreto - Determinación del contenido de aire del concreto fresco por el método volumétrico

42. NMX-C-162-ONNCCE-2014, Industria de la construcción - Concreto hidráulico - Determinación 
de la masa unitaria, cálculo del rendimiento y contenido de aire del concreto fresco por el método gravimétrico.

43. NMX-C-163-onncce-2019, Industria de la construcción - Concreto hidráulico - Determinación de la resistencia a la tensión por compresión diametral de cilindros de concreto - Método de ensayo

44. NMX-C-169-ONNCCE-2009 Industria de la construcción - Concreto - Extracción de especímenes cilíndricos o prismáticos de concreto hidráulico endurecido.

45. NMX-C-173-ONNCCE-2010, Industria de la construcción - Concreto hidráulico - Determinación de la variación en la longitud de especímenes de mortero de cemento y de concreto endurecidos

46. NMX-C-191-ONNCCE-2015 Industria de la construcción - Concreto - Determinación de la resistencia a la flexión del concreto usando una viga simple con carga en los tercios del claro

47. NMX-C-255-ONNCCE-2013. Industria de la construcción - Aditivos químicos para concreto Especificaciones y métodos de ensayo

48. NMX-C-283-ONNCCE-2017, Industria de la construcción- Agua para concreto-Métodos de prueba

49. NMX-C-414-ONNCCE-2017, Industria de la construcción - Cementantes hidráulicos Especificaciones y métodos de ensayo

50. NMX-C-435-ONNCCE-2010 Industria de la construcción - Concreto hidráulico - Determinación de la temperatura del concreto fresco

51. NMX-C-495-ONNCCE-2015, Industria de la construcción - Durabilidad de estructuras de concreto reforzado - Medición de potenciales de corrosión del acero de refuerzo sin revestir, embebido en concreto - Especificaciones y método de ensayo

52. NMX-C-501-ONNCCE-2015, Industria de la construcción - Durabilidad de estructuras de concreto reforzado - Medición de velocidad de corrosión en campo especificaciones y método de ensayo

53. NMX-C-504-ONNCCE-2015, Industria de la construcción - Determinación de la absorción capilar en concreto hidráulico - Método de ensayo

54. NMX-C-505-ONNCCE-2016, Industria de la construcción - Inspección preliminar de daños en estructuras de concreto hidráulico con criterios de durabilidad - Procedimientos

55. NMX-C-514-ONNCCE-201, Industria de la construcción - Resistividad eléctrica del concreto hidráulico - Especificaciones y métodos de ensayo

56. NMX-C-515-ONNCCE-2016, Industria de la construcción - Concreto hidráulico - Durabilidad Determinación de la profundidad de carbonatación en concreto hidráulico - Especificaciones y método de ensayo

57. NMX-C-518-ONNCCE-2016, Industria de la construcción - Durabilidad de estructuras de concreto reforzado - Origen del deterioro - Procedimientos de preparación y limpieza de superficies para reparación

58. NMX-C-523-ONNCCE-2016, Industria de la construcción - Durabilidad de estructuras de 
concreto reforzado - Concentración de cloruros solubles en agua y ácido - Determinación en concreto hidráulico - Método de extracción y método de determinación por ion selectivo

59. NMX-C-530-ONNCCE-2018 Industria de la construcción - Durabilidad - Norma general de durabilidad de estructuras de concreto reforzado - Criterios y especificaciones

60. UNE 77042:2015 Calidad del agua. Determinación de cloruros. Método potenciométrico.

61. UNE 83318:1994 Ensayos de hormigón. Determinación de los cambios de longitud.

62. UNE 83952:2008 Durabilidad del hormigón. Aguas de amasado y aguas agresivas. Determinación del $\mathrm{pH}$. Método potenciométrico.

63. UNE 83956:2008 Durabilidad del hormigón. Aguas de amasado y aguas agresivas. Determinación del contenido en ion sulfato

64. UNE 83958:2014 Durabilidad del hormigón. Aguas de amasado y aguas agresivas. Determinación del contenido en cloruros.

65. UNE 83963:2008 Durabilidad del hormigón. Suelos agresivos. Determinación del contenido en ión sulfato.

66. UNE 83702:1994 IN Materiales de reparación. Preparación de superficies de hormigón armado para su reparación. Recomendaciones de uso.

67. UNE 83982:2008 Durabilidad del hormigón. Métodos de ensayo. Determinación de la absorción de agua por capilaridad del hormigón endurecido. Método Fagerlund.

68. UNE 83988-1:2008 Durabilidad del hormigón. Métodos de ensayo. Determinación de la resistividad eléctrica. Parte 1: Método directo (método de referencia).

69. UNE 83988-2:2014 Durabilidad del hormigón. Métodos de ensayo. Determinación de la resistividad eléctrica. Parte 2: Método de las cuatro puntas o de Wenner.

70. UNE 112083:2010 Medición del potencial de corrosión libre en estructuras de hormigón armado.

71. UNE 146406:2018 Determinación del contenido, tamaño máximo característico y módulo granulométrico del árido grueso en el hormigón fresco.

72. UNE-EN 934-1:2009 Aditivos para hormigones, morteros y pastas. Parte 1: Requisitos comunes

73. UNE-EN 197-1:2011 Cemento. Parte 1: Composición, especificaciones y criterios de conformidad de los cementos comunes.

74. UNE-EN 1008:2007 Agua de amasado para hormigón. Especificaciones para la toma de muestras, los ensayos de evaluación y aptitud al uso incluyendo las aguas de lavado de las instalaciones de reciclado de la industria del hormigón, así como el agua de amasado para hormigón.

75. UNE-EN 12350-2:2020 Ensayos de hormigón fresco. Parte 2: Ensayo de asentamiento.

76. UNE-EN 12350-6:2020 Ensayos de hormigón fresco. Parte 6: Densidad.

77. UNE-EN 12350-7:2020 Ensayos de hormigón fresco. Parte 7: Contenido de aire. Métodos de 
presión.

78. UNE-EN-12390 Testing hardened concrete.

79. UNE-EN 12390-3:2020 Ensayos de hormigón endurecido. Parte 3: Determinación de la resistencia a compresión de probetas.

80. UNE-EN 12390-5:2020 Ensayos de hormigón endurecido. Parte 5: Resistencia a flexión de probetas.

81. UNE-EN 12504-1:2020 Ensayos de hormigón en estructuras. Parte 1: Testigos. Extracción, examen y ensayo a compresión.

82. UNE-EN 12620:2003+A1:2009 Áridos para hormigón.

83. UNE-EN 13396:2005 Productos y sistemas para la protección y reparación de estructuras de hormigón. Métodos de ensayo. Medición de la penetración de los iones cloruro

84. UNE-EN 13412:2008 Productos y sistemas para la protección y reparación de estructuras de hormigón. Métodos de ensayo. Determinación del módulo de elasticidad en compresión.

85. UNE-EN 14617-4:2012 Piedra aglomerada. Métodos de ensayo. Parte 4: Determinación de la resistencia a la abrasión.

86. UNE-EN 14629:2007 Productos y sistemas para la protección y reparación de estructuras de hormigón. Métodos de ensayo. Determinación del contenido en cloruros en el hormigón endurecido.

87. UNE-EN 14630:2007 Productos y sistemas para la protección y reparación de estructuras de hormigón. Métodos de ensayo. Determinación de la profundidad de carbonatación en un hormigón endurecido por el método de la fenolftaleína.

88. Quesada G., "Procedimientos de reparación”, Capítulo 06 del libro: Manual de rehabilitación de Estructuras de Hormigón. Reparación, Refuerzo y Protección, Eds. P. Helene y F. Pereira, Red Rehabilitar XV. F del Cyted, ISBN 85-903707-1-2. pp. 289-338, $1^{\text {a }}$ Edición, Octubre de 2003.

89. Troconis O., y colaboradores, Manual de inspección y diagnóstico en estructuras de hormigón armado, CYTED. Río de Janeiro, Brasil. 1998.

90. Castro P., "El umbral de los cloruros para despasivar el acero de refuerzo. Criterios y resultados en el mundo", Revista Construcción y Tecnología del IMCyC, Vol. 13, No. 152, pp. 26-33, Enero de 2001.

91. Mendoza R., Castro P. "Validez de los conceptos y modelos vigentes de vida de servicio de estructuras de concreto ante los efectos del cambio climático global. Situación actual.

92. Jhon W. Oldfield., "Electrochemical Theory of Galvanic Corrosion", Galvanic Corrosion, Ed. Harvey P. Hack. pp. 5-22, 1986.

93. Pérez L. "Vida útil residual de estructuras de hormigón armado afectadas por corrosión". Septiembre, 2010. 


\section{APÉNDICE A}

A continuación, se presentan los criterios de evaluación para los valores obtenidos de potencial de corrosión, velocidad de corrosión, resistividad eléctrica y el umbral de cloruros para producir corrosión.

Tabla A1. Criterios de evaluación de potencial de corrosión $\left(\mathrm{E}_{\mathrm{corr}}\right)$

\begin{tabular}{|c|c|}
\hline Potencial (mV vs CSE) & Condición \\
\hline $\mathrm{E}_{\text {corr }}>-200$ & Menos del $10 \%$ de probabilidad de corrosión \\
\hline$-200<\mathrm{E}_{\text {corr }}<-350$ & Corrosión incierta \\
\hline $\mathrm{E}_{\text {corr }}<-350$ & Más del $90 \%$ de probabilidad de corrosión \\
\hline
\end{tabular}

Tabla A2. Criterios de evaluación de velocidad de corrosión ( $\left.\mathrm{i}_{\text {corr }}\right)$

\begin{tabular}{|c|c|}
\hline $\mathbf{j}$ corr $\left(\boldsymbol{\mu} \mathbf{A} / \mathbf{c m}^{2}\right)$ & Nivel de corrosión \\
\hline$<0,1$ & Despreciable \\
\hline $0,1-0,5$ & Moderado \\
\hline $0,5-1$ & Elevado \\
\hline$>1$ & Muy elevado \\
\hline
\end{tabular}

Tabla A3. Criterios de evaluación de resistividad $(\rho)$

\begin{tabular}{|c|c|}
\hline Resistividad (K囚.cm) & Riesgo de corrosión \\
\hline$\rho>200$ & Poco riesgo \\
\hline $200>\rho>10$ & Riesgo moderado \\
\hline$\rho<10$ & Alto riesgo \\
\hline
\end{tabular}

Tabla A4. Criterios de evaluación de umbrales de cloruros

\begin{tabular}{|cc|c|}
\hline Relación a/c & $\begin{array}{c}\text { Rango de umbrales } \\
\text { de cloruro usando } \\
\text { imedia } \\
\text { (\% por peso de } \\
\text { cemento) }\end{array}$ & $\begin{array}{c}\text { Promedio de umbrales } \\
\text { de cloruro usando imedia } \\
(\% \text { por peso de cemento) }\end{array}$ \\
\hline 0,46 & $0,40-0,61$ & 0,50 \\
0,53 & $0,65-1,10$ & 0,87 \\
\hline 0,59 & $0,49-0,61$ & 0,55 \\
0,70 & $0,33-0,47$ & 0,40 \\
\hline 0,76 & $0,30-0,43$ & 0,76 \\
\hline
\end{tabular}




\title{
APÉNDICE B
}

\section{B.1 - Ejemplo de formato para realizar mantenimiento}

\author{
FORMATO PARA LA VERIFICACIÓN DE LA FUNCIONALIDAD DE UNA \\ REPARACIÓN
}

a) Datos generales

Lugar (ubicación):

Progreso, Yucatán, México.

Estructura:

Puente de Yucalpetén.

Tipo de reparación:

Reparación eventual por parcheo en tanto se gestionan fondos para aplicar un sistema integral.

Fecha de la reparación: 2 de mayo del 2013.

Fecha de la recepción de la reparación: 1 de junio de 2012.

Edad de la reparación:

1 año.

Ambiente:

Tropical marino, atmósfera agresiva.

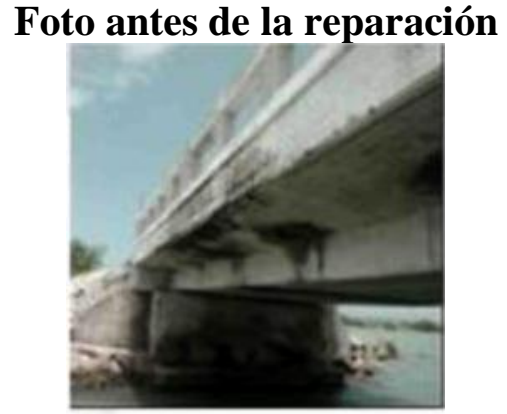

Observaciones generales:

Desprendimientos causados por humedades

\section{Composición virtual después de la reparación}

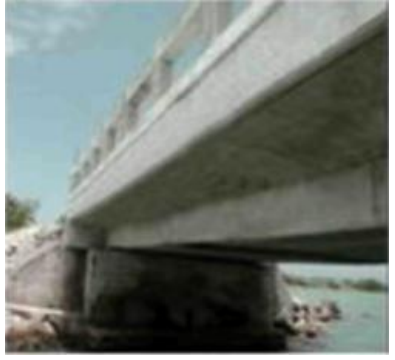

Observaciones generales: Parcheo con poca supervisión sin fotos testigos del procedimiento

b) Plan de mantenimiento (especificaciones)

1) Pruebas de carbonatación

a. Verificar la profundidad de carbonatación cada 6 meses con fenolftaleína o timolftaleína.

b. Si durante el primer año de la reparación el avance es mayor a $10 \mathrm{~mm}$, debe replantearse el plan de seguimiento y diseñar nuevas acciones de conservación.

2) Pruebas de contenido de cloruro

a. Deben hacerse perfiles de cloruros en zonas selectivas de la reparación cada año. Sí el umbral crítico de diseño para producir corrosión tiende a sobrepasarse durante el período de garantía de la reparación, debe replantearse el seguimiento de la funcionalidad de la reparación

b. Cuando haya una tendencia anual hacia valores de concentración peligrosos, deben emprenderse nuevas acciones correctivas, aunque no se haya sobrepasado el umbral. 
3) Resistividad eléctrica del concreto

a. Si la reparación fue hecha con concreto, debe verificarse cada seis meses la resistividad del concreto de la reparación. Si ésta es menor de 5,000 K $\Omega$-cm, o se acerca a este valor durante las evaluaciones, deben emprenderse nuevas acciones de conservación, después de analizar los resultados de las pruebas anteriores.

b. Si la reparación es hecha con otros materiales, debe fijarse un criterio mínimo de funcionalidad

4) Potencial de corrosión del acero en las zonas reparadas y aledañas

a. Deben verificarse los potenciales de corrosión cada seis meses en las zonas reparadas y aledañas para detectar posibles acciones galvánicas de la reparación.

b. Si el potencial muestra una tendencia hacia valores menores de $-350 \mathrm{mV}$ vs. $\mathrm{Cu} / \mathrm{CuSO}_{4}$ debe replantearse el esquema de seguimiento de la funcionalidad de la reparación y plantear posibles acciones correctivas.

5) Velocidad de corrosión del acero en las zonas reparadas y aledañas

a. Deben verificarse las velocidades de corrosión cada seis meses en las zonas reparadas y aledañas para detectar posibles despasivaciones o efectos galvánicos

b. Si la velocidad de corrosión supera o tiende a superar en mediciones sucesivas el valor del umbral $\left(0.1 \mu \mathrm{A} / \mathrm{cm}^{2}\right)$ debe replantearse el seguimiento de la funcionalidad de la reparación y planear nuevas acciones correctivas. Esta prueba junto con las anteriores normarán el criterio del evaluador.

6) Agrietamientos en el concreto

a. Debe hacerse un seguimiento trimestral de los agrietamientos, principalmente en las interfases de la reparación

b. Las grietas por contracción deben repararse en cuanto aparezcan con lechadas de cal.

c. Otros tipos de grieta deben ser consultadas con un perito en estructuras para verificar si son consecuencia de la reparación

d. En función de los resultados con el tiempo se planearán nuevas acciones preventivas y/o correctivas

7) Cambios de nivel

a. Es posible detectar cambios de nivel debidos a reparación defectuosa que ocasionen humedades y eventual deterioro de la reparación

b. Es posible detectar cambios de uso que propicien estancamiento y problemas de nivel que también generen deterioro

c. Ambos casos deben evaluarse trimestralmente y en caso de observarse anomalías, ya sea por causa de la reparación o de la estructura misma, deben tomarse acciones preventivas oportunas 
c) Mediciones:

\begin{tabular}{|c|c|c|c|c|c|c|}
\hline Mediciones & $\begin{array}{c}\text { Fecha } \\
\text { 3-05-2012 }\end{array}$ & $\begin{array}{c}\text { Fecha } \\
\text { 3-11-2012 }\end{array}$ & $\begin{array}{c}\text { Fecha } \\
\text { 3-05-2013 }\end{array}$ & $\begin{array}{c}\text { Fecha } \\
\text { 3-08-2013 }\end{array}$ & $\begin{array}{c}\text { Fecha } \\
\text { 3-11-2013 }\end{array}$ & Observaciones \\
\hline $\begin{array}{l}\text { Carbonatación } \\
\qquad(\mathrm{mm})\end{array}$ & 0 & 3 & 10 & 14 & 17 & $\begin{array}{c}\text { Carbonatación } \\
\text { rápida, peligro } \\
\text { de llegar pronto } \\
\text { al acero. }\end{array}$ \\
\hline $\begin{array}{l}\text { Cloruros (nivel } \\
\text { barras) } \\
\text { (\% por peso de } \\
\text { cemento) }\end{array}$ & 0.1 & 0.3 & 0.7 & 0.8 & 1.0 & $\begin{array}{l}\text { Umbral } \\
\text { superado, se } \\
\text { requiere } \\
\text { intervención. }\end{array}$ \\
\hline $\begin{array}{l}\text { Resistividad } \\
(\mathrm{K} \Omega-\mathrm{cm})\end{array}$ & 8,000 & 7,000 & 5,000 & 3,000 & 3,000 & $\begin{array}{l}\text { Resistividad } \\
\text { muy baja. } \\
\text { Mucha } \\
\text { conductividad } \\
\text { en zona de } \\
\text { aerosol, nivel } \\
\text { peligroso. }\end{array}$ \\
\hline $\begin{array}{l}\text { Agrietamientos } \\
\qquad(\mathrm{mm})\end{array}$ & 0 & 0 & 0.3 & 0.5 & 0.8 & $\begin{array}{c}\text { Nivel aceptable } \\
\text { de } \\
\text { agrietamiento }\end{array}$ \\
\hline $\begin{array}{l}\text { Cambios de } \\
\text { nivel }(\%)\end{array}$ & 3 & 3 & 5 & 5 & 5 & $\begin{array}{c}\text { Cambio de } \\
\text { nivel debido al } \\
\text { aumento de } \\
\text { tráfico y } \\
\text { encharcamiento } \\
\text { en zonas } \\
\text { críticas. }\end{array}$ \\
\hline $\begin{array}{l}\text { Potencial de } \\
\text { corrosión }(\mathrm{mV} \\
\left.\text { vs. } \mathrm{Cu} / \mathrm{CuSO}_{4}\right)\end{array}$ & -200 & -220 & -350 & -375 & -380 & $\begin{array}{c}\text { Potencial } \\
\text { activo, peligro } \\
\text { inminente de } \\
\text { falla en la } \\
\text { repara }\end{array}$ \\
\hline $\begin{array}{l}\text { Velocidad de } \\
\text { corrosión } \\
\left(\mu \mathrm{A} / \mathrm{cm}^{2}\right)\end{array}$ & 0.01 & 0.07 & 0.2 & 0.3 & 0.35 & $\begin{array}{l}\text { Velocidad de } \\
\text { corrosión } \\
\text { activa, } \\
\text { intervención } \\
\text { inmediata }\end{array}$ \\
\hline
\end{tabular}

Observaciones generales: Al finalizar 2.5 años de la puesta en servicio es requerido realizar una intervención, esto deberá hacerse desde el inicio del $2^{\circ}$ año, como medida preventiva. Desafortunadamente la falta de experiencia y de presupuesto ocasiona pérdidas de tiempo y los problemas avanzan. Se recomienda una inspección complementaria e intervenir la estructura con un sistema diferente de protección que garantice una durabilidad mayor. 